Supporting Information

\title{
FeNi Nanoalloys Encapsulated in N-doped CNTs Tangled with N-doped Carbon Nanosheets as Efficient Multifunctional Catalysts for Overall Water Splitting and Rechargeable Zn-air Batteries
}

Jin-Tao Ren, ${ }^{a, b}$ Lei Chen,,$^{a, b}$ Yan-Su Wang, ${ }^{a, b}$ Wen-Wen Tian, ${ }^{a, b}$ Li-Jiao Gao, ${ }^{a, b}$ and Zhong-Yong Yuan ${ }^{a, b, *}$

${ }^{a}$ National Institute for Advanced Materials, School of Materials Science and

Engineering, Nankai University, Tianjin 300350, China.

${ }^{b}$ Key Laboratory of Advanced Energy Materials Chemistry (Ministry of Education), Collaborative Innovation Center of Chemical Science and Engineering (Tianjin),

Nankai University, Tianjin 300071, China.

*Corresponding author: Professor Zhong-Yong Yuan, E-mail: zyyuan@nankai.edu.cn.

School of Materials Science and Engineering, Nankai University, Tongyan Road 38, Haihe Educational Park, Tianjin 300350, China

Supplementary Figures S1-S47, Supplementary Tables S1-S5, Supplementary References 1-78. 


\section{Supplementary Figures}
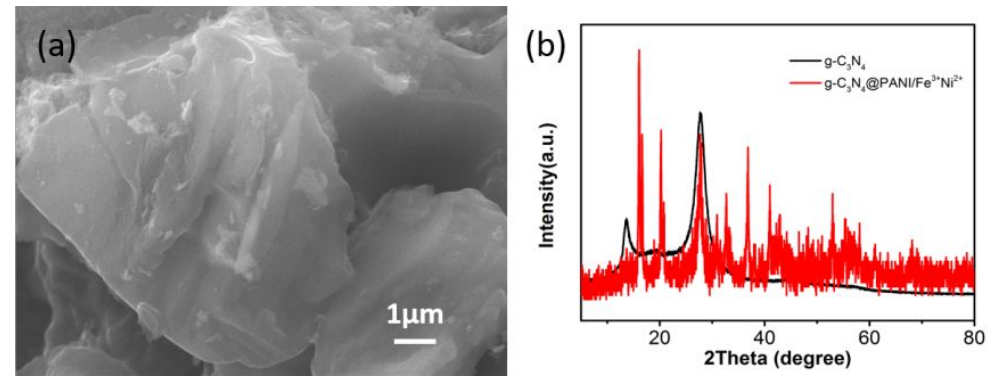

Figure S1. (a) SEM image of $g-\mathrm{C}_{3} \mathrm{~N}_{4}$. (b) XRD patterns of typical g- $\mathrm{C}_{3} \mathrm{~N}_{4}$ and the fabricated g$\mathrm{C}_{3} \mathrm{~N}_{4} @ \mathrm{PANI} / \mathrm{Fe}^{3+} \mathrm{Ni}^{2+}$. From the SEM image, the typical g- $\mathrm{C}_{3} \mathrm{~N}_{4}$ exhibits the bulk structure. For the XRD pattern, the centered diffraction peaks located at about $13.1^{\circ}$ and $27.3^{\circ}(2 \theta)$ for $g-\mathrm{C}_{3} \mathrm{~N}_{4}$ attribute to the (100) and (002) peaks for the typical graphitic carbon nitride materials. After the coating of polyaniline layer and the adsorption of metal salts, the typical diffraction peaks of graphitic carbon nitride for $\mathrm{g}-\mathrm{C}_{3} \mathrm{~N}_{4}$ are still remained, indicating the robust structure.

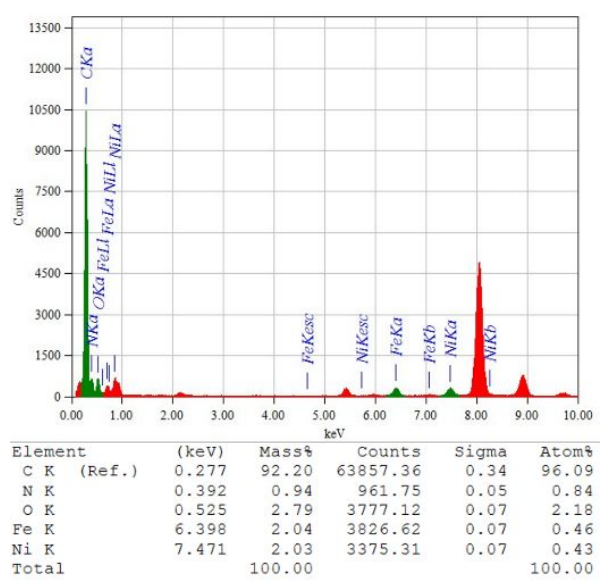

Figure S2. TEM-EDS spectrum of FeNi@N-CNT/NCSs.

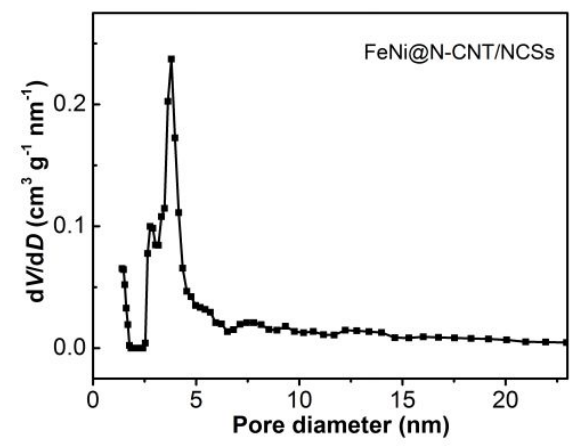

Figure S3. Pore size distribution curve of FeNi@N-CNT/NCSs. 

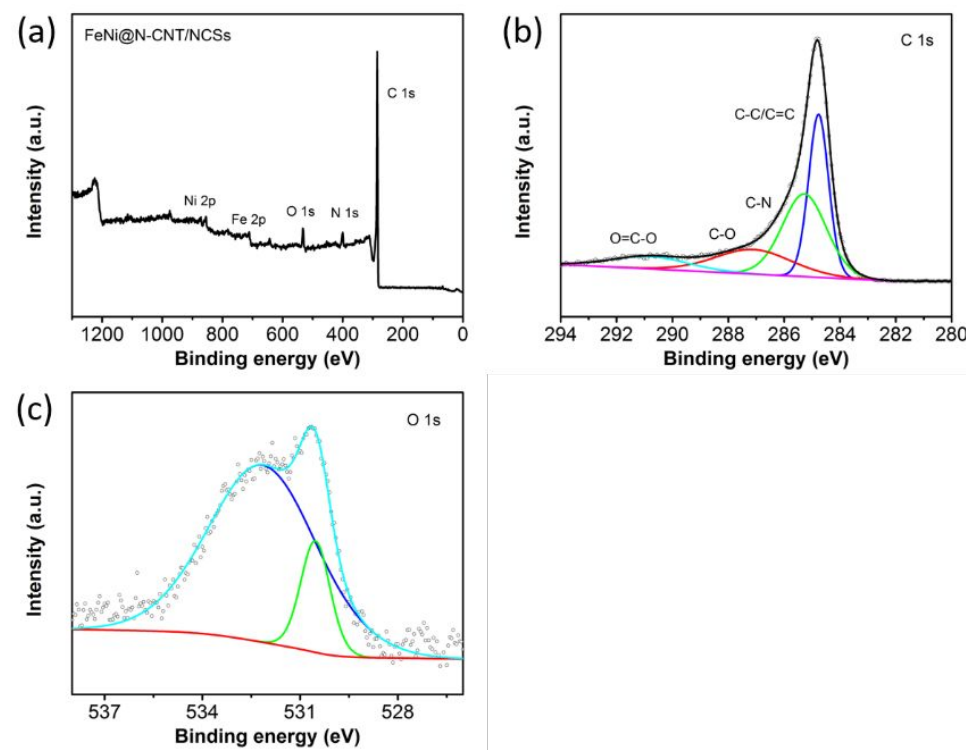

Figure S4. (a) Survey XPS spectra for FeNi@N-CNT/NCSs. The corresponding high-resolution XPS spectra of $\mathrm{C} 1 \mathrm{~s}$ region (b), $\mathrm{O} 1 \mathrm{~s}$ region (c). With respect to the $\mathrm{C} 1 \mathrm{~s}$ spectrum, the fitted four peaks centered at 784.8, 285.3, 287.2, and $290.7 \mathrm{eV}$ correspond to $\mathrm{C}-\mathrm{C} / \mathrm{C}=\mathrm{C}, \mathrm{C}-\mathrm{N}, \mathrm{C}-\mathrm{O}$, and $\mathrm{O}=\mathrm{C}-$ $\mathrm{O}$ species, respectively. For high-resolution $\mathrm{O} 1 \mathrm{~s}$ region, the apparent peaks at 530.6 and $532.4 \mathrm{eV}$ associated with the oxygen species in carbon frameworks, and the surface physisorbed and chemisorbed water. And there no $\mathrm{O}$ species related to metal oxides are observed. Such results further indicate the formation of metallic FeNi alloy.
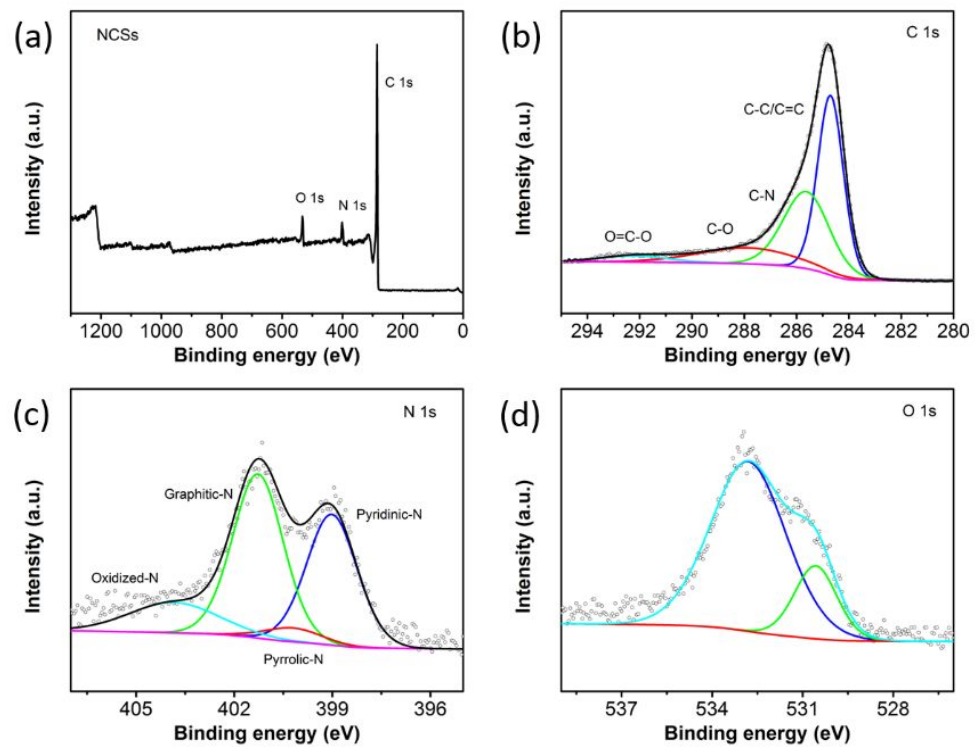

Figure S5. (a) Survey XPS spectra for NCSs. The corresponding high-resolution XPS spectra of $\mathrm{C} 1 \mathrm{~s}$ region (b), $\mathrm{N}$ 1s region (c), $\mathrm{O} 1 \mathrm{~s}$ region (d). The XPS survey spectrum of NCSs contains only $\mathrm{C}, \mathrm{N}$, and $\mathrm{O}$ species without other impurities. The XPS spectra of $\mathrm{C} 1 \mathrm{~s}$ can be deconvoluted into four components including $\mathrm{C}-\mathrm{C} / \mathrm{C}=\mathrm{C}, \mathrm{C}-\mathrm{N}, \mathrm{C}-\mathrm{O}$, and $\mathrm{O}=\mathrm{C}-\mathrm{O}$, respectively. High-resolution $\mathrm{N} 1 \mathrm{~s}$ spectrum can be fitted into four components, namely, pyridinic-N, pyrrolic-N, graphitic-N, and oxidized-N, respectively. With respect to the $\mathrm{O} 1 \mathrm{~s}$, the fitted peaks is associated with the unsaturated oxygen species with $\mathrm{C}=\mathrm{O}$ bonding, and the oxygen groups formed from adsorbed water within the surface. 


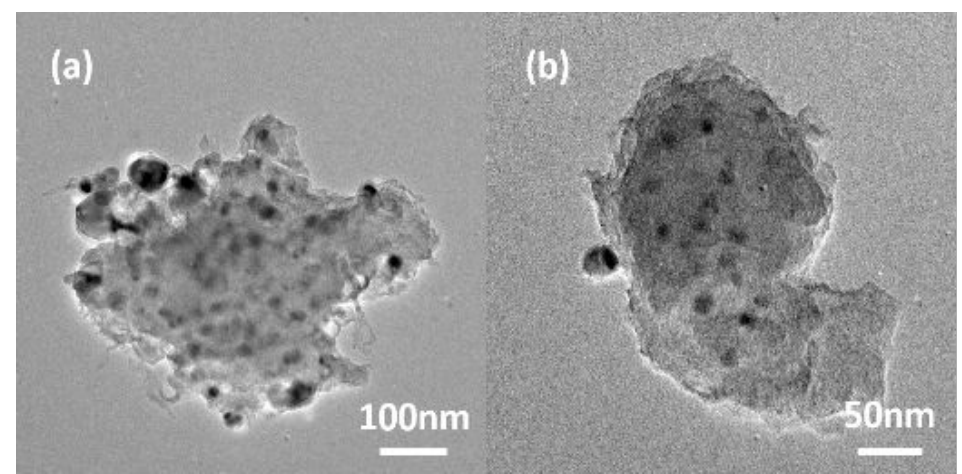

Figure S6. (a-b) TEM images of FeNi/NC.

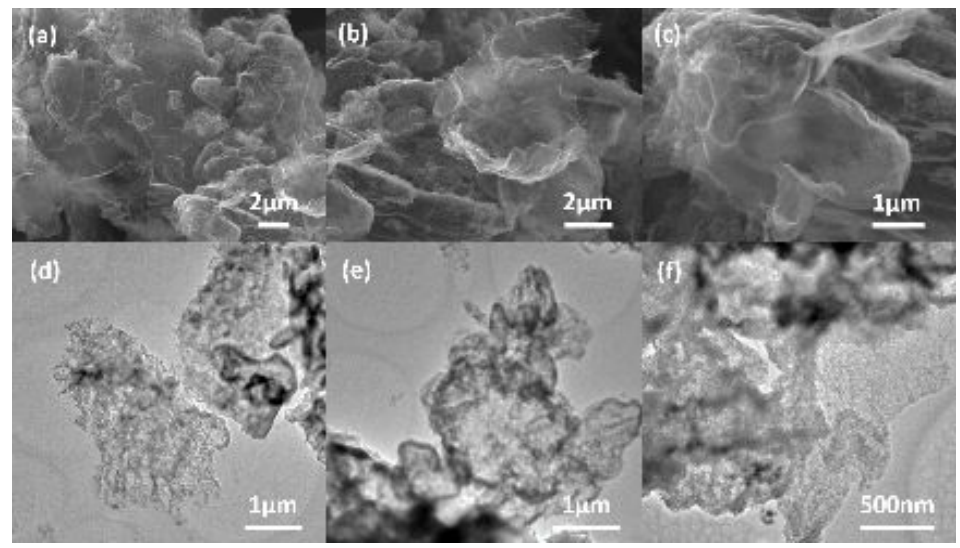

Figure S7. (a-c) SEM, (d-f) TEM images of NCSs.

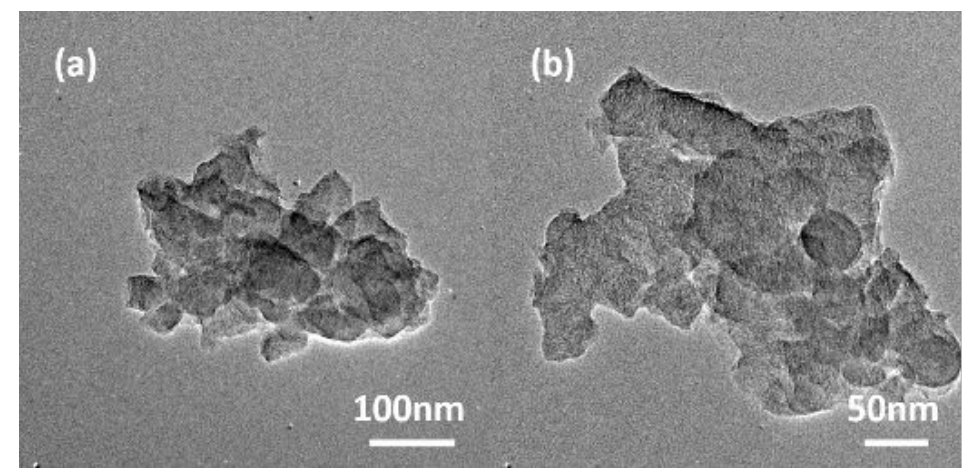

Figure S8. (a-b) TEM images of NC.

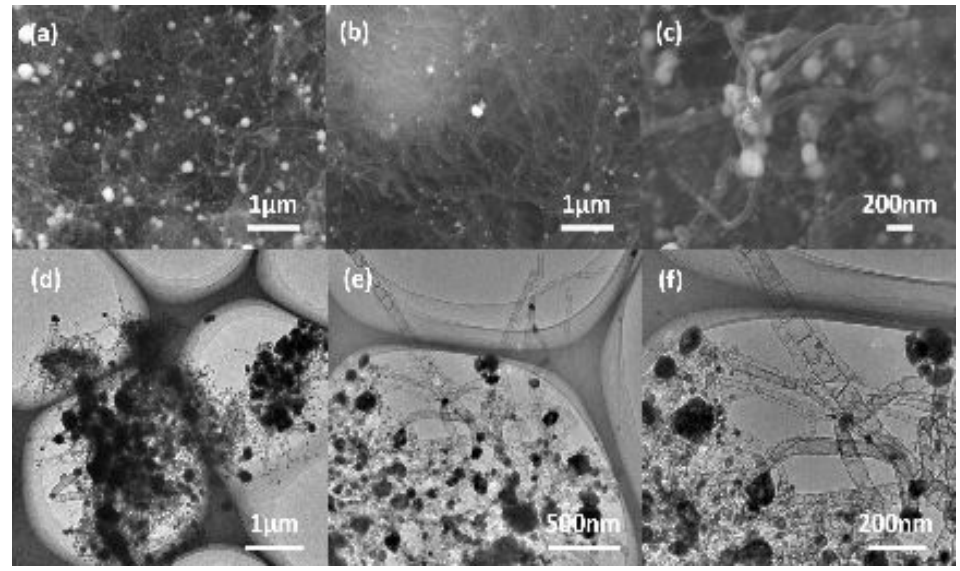

Figure S9. (a-c) SEM, (d-f) TEM images of FeNi@N-CNT. 


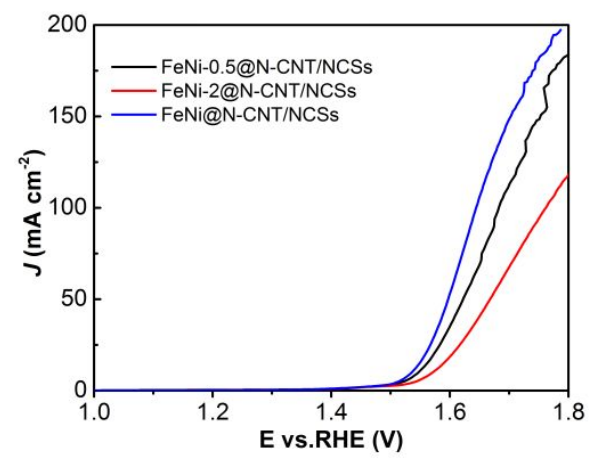

Figure S10. OER polarization curves of FeNi-0.5@N-CNT/NCSs, FeNi-2@N-CNT/NCSs and FeNi@N-CNT/NCSs in 1.0 M KOH.

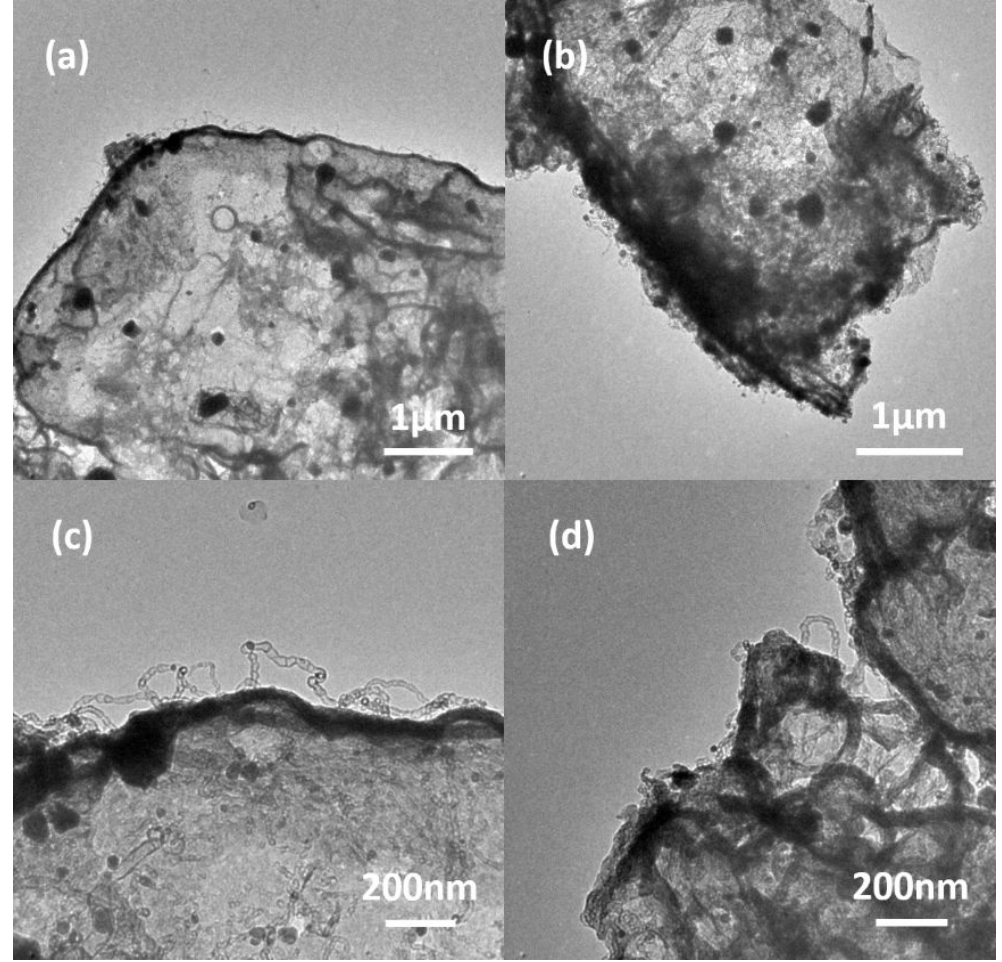

Figure S11. (a-d) TEM images of FeNi-0.5@N-CNT/NCSs. 


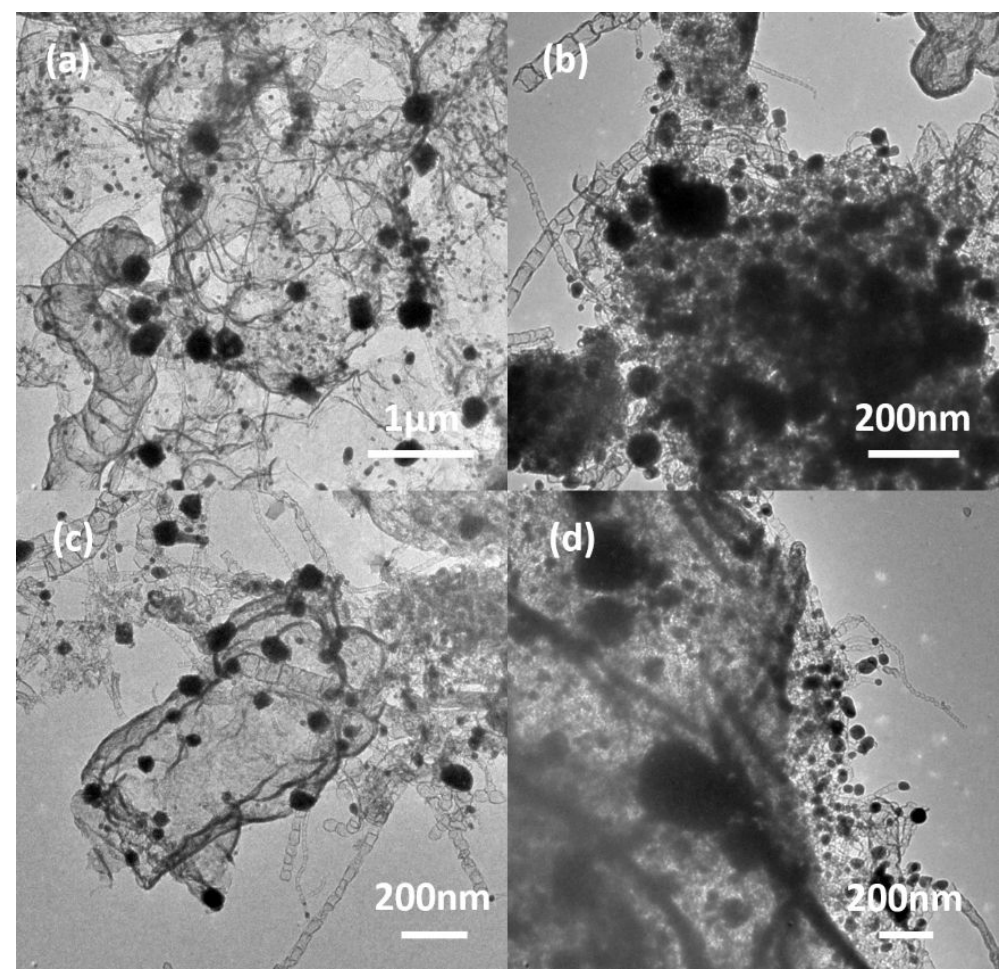

Figure S12. (a-d) TEM images of FeNi-2@N-CNT/NCSs.
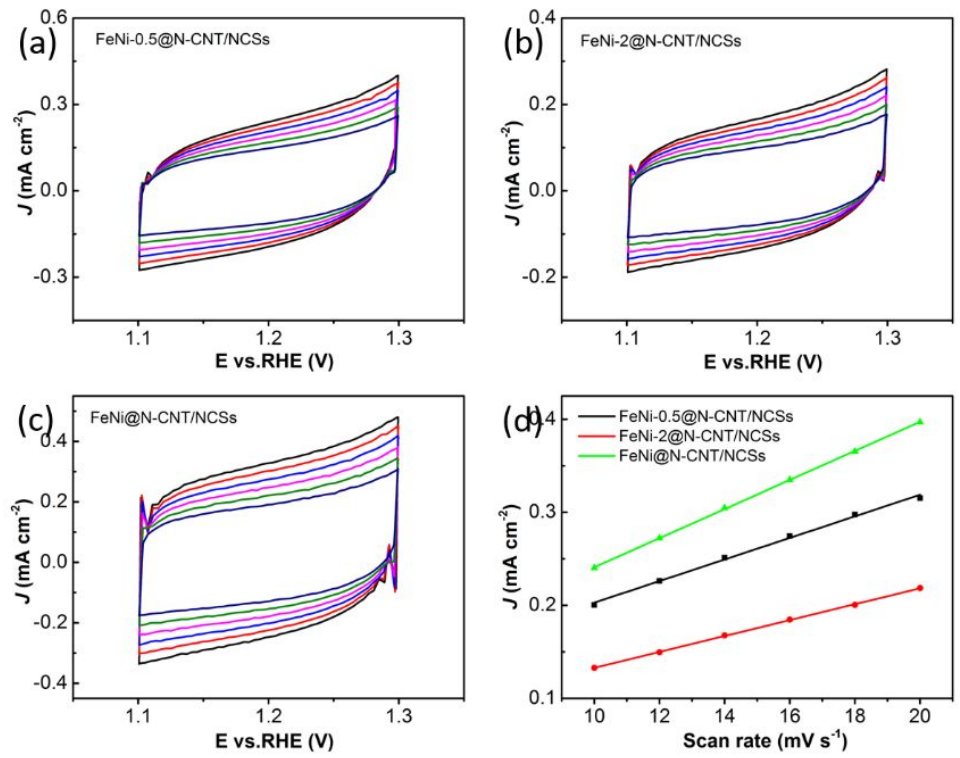

Figure S13. (a-c) Cyclic voltammograms of FeNi-0.5@N-CNT/NCSs, FeNi-2@N-CNT/NCSs, and FeNi@N-CNT/NCSs measured at different scan rates from 10 to $20 \mathrm{mV} \mathrm{s}^{-1}$. (d) And the corresponding plots of the current densities at $1.260 \mathrm{~V} v s$. the scan rates of the developed catalysts. By calculating the slope value of the current density against the scan speeds, the electrochemical double-layer capacitance $\left(C_{\mathrm{dl}}\right)$ was calculated to be 11.6, 8.5, and $15.9 \mathrm{mF} \mathrm{cm}{ }^{-2}$ for FeNi-0.5@NCNT/NCSs, FeNi-2@N-CNT/NCSs, andFeNi@N-CNT/NCSs, respectively.

ECSA calculation: The electrochemically active surface area (ECSA) can be determined using the capacitance $\left(C_{\mathrm{dl}}\right)$. The specific capacitance for a flat surface is generally found to be in the range of $20 \sim 60 \mu \mathrm{F} \mathrm{cm}^{-2}$. In there, $40 \mu \mathrm{F} \mathrm{cm} \mathrm{cm}^{-2}$ was used in the following calculations of the ECSA as literatures generally did. ${ }^{1-2}$

The following formula was used to calculate ECSA: 


$$
\mathrm{ECSA}=\frac{\mathrm{C}}{40 \mu \mathrm{F} \mathrm{cm}^{-2} \text { per } \mathrm{cm}^{-2}}
$$

Therefore, the ECSA for FeNi-0.5@N-CNT/NCSs, FeNi-2@N-CNT/NCSs, and FeNi@NCNT/NCSs were calculated to be 290, 212.5 and $397.5 \mathrm{~cm}^{2}$, respectively. Such higher ECSA for the standard FeNi@N-CNT/NCSs promises the enlarged catalytic surface area and the better transfer of reactants/products, and thus the enhanced OER activity.

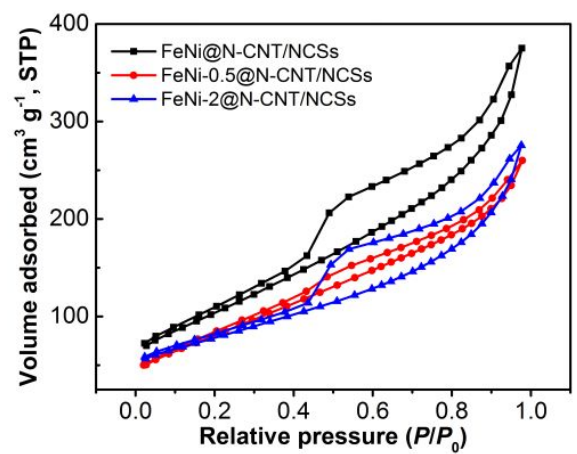

Figure S14. $\mathrm{N}_{2}$ adsorption-desorption curves of FeNi@N-CNT/NCSs, FeNi-0.5@N-CNT/NCSs and FeNi-2@N-CNT/NCSs. The BET specific surface area $\left(S_{\mathrm{BET}}\right)$ can be determined to be 383, 306 , and $276 \mathrm{~m}^{2} \mathrm{~g}^{-1}$. The largest $S_{\mathrm{BET}}$ value of FeNi@N-CNT/NCSs indicates that the appropriate feeding amount of metal salts favors the formation of the optimal morphology for the final sample. Such 3D hierarchical morphology would provide more inner active sites and permit the contact and diffusion of reactants, which is favorable for the enhanced electocatalytic performance.

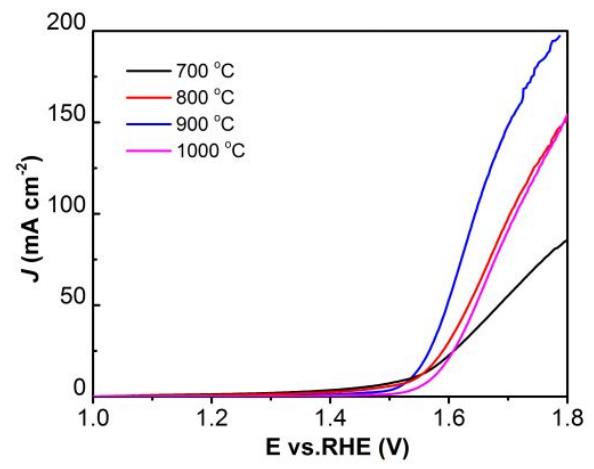

Figure S15. LSV curves of FeNi@N-CNT/NCSs treated at different temperature of 700, 800, 900, and $1000{ }^{\circ} \mathrm{C}$.

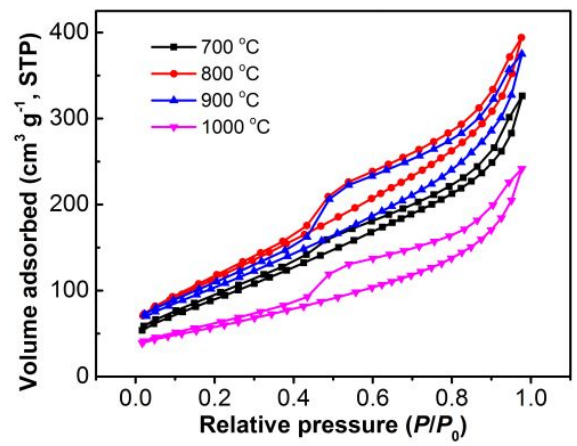

Figure S16. $\mathrm{N}_{2}$ adsorption-desorption curves of FeNi@N-CNT/NCSs prepared at $700 / 800 / 900 / 1000{ }^{\circ} \mathrm{C}$. And the corresponding BET specific surface area $\left(S_{\mathrm{BET}}\right)$ are $339,425,383$, 
$210 \mathrm{~m}^{2} \mathrm{~g}^{-1}$ for FeNi@N-CNT/NCSs prepared at 700/800/900/1000 ${ }^{\circ} \mathrm{C}$. The incomplete pyrolysis at low temperature results in lower surface area, and the enhanced pyrolysis temperature leads to the severely stacking degree and obtains the lower surface area. Nevertheless, the higher carbonization temperature would facilitate the enhancement of graphitic degree of obtained carbon materials, which is favorable for the electric conductivity during electrochemical reactions.

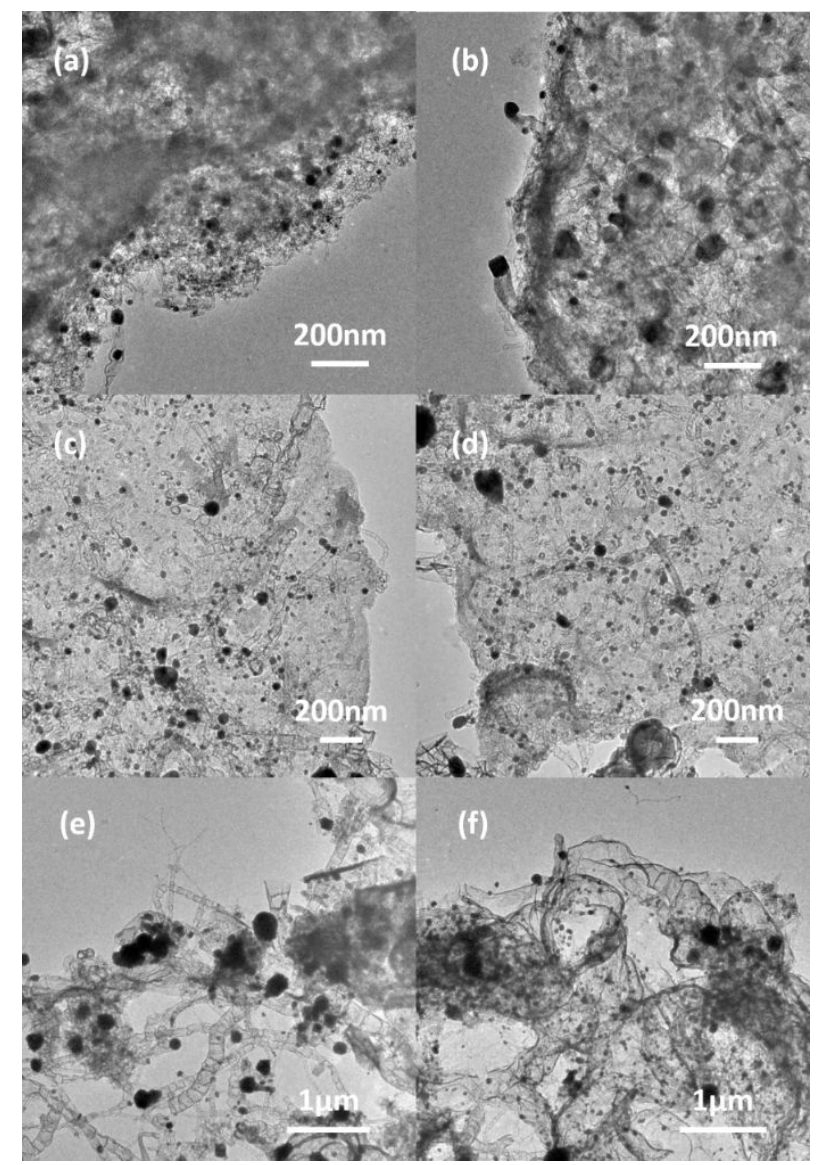

Figure S17. TEM images of FeNi@N-CNT/NCSs prepared at $700{ }^{\circ} \mathrm{C}(\mathrm{a}-\mathrm{b}), 800{ }^{\circ} \mathrm{C}(\mathrm{c}-\mathrm{d})$, and 1000 ${ }^{\circ} \mathrm{C}$ (e-f), respectively. As observed on TEM images, the increased particle size of metal alloys are detected along with the enhancement of pyrolysis temperature. Especially, largest particles are obtained by the samples treated at $1000^{\circ} \mathrm{C}$. 

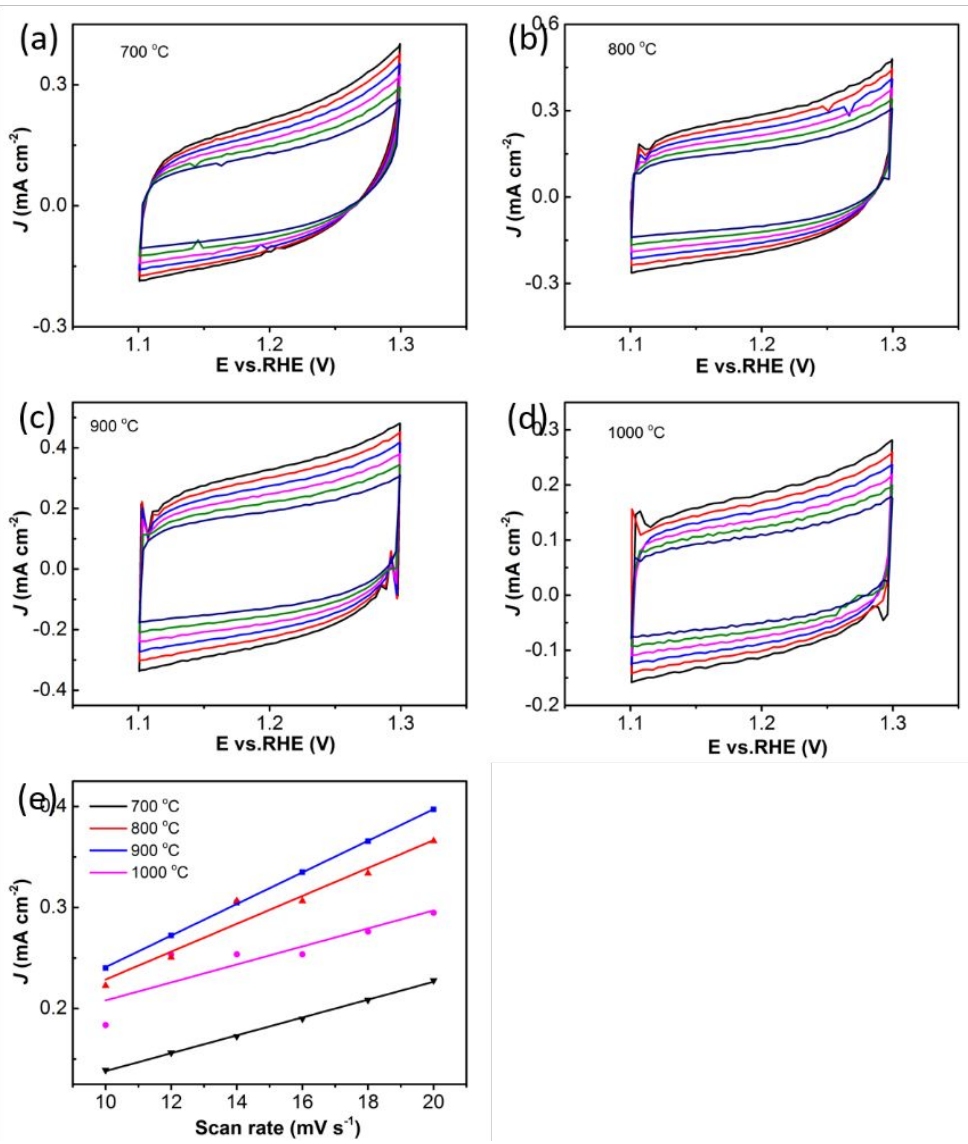

Figure S18. Cyclic voltammograms of FeNi@N-CNT/NCSs treated at different temperatures of 700 (a), 800 (b), 900 (c), and $1000{ }^{\circ} \mathrm{C}$ (d) measured at different scan rates from 10 to $20 \mathrm{mV} \mathrm{s}^{-1}$. (e) And the plots of the current densities at $1.260 \mathrm{~V} v s$. the scan rates of the developed catalysts. On the basis of the corresponding plots, the $C_{\mathrm{dl}}$ of those samples are $8.9,13.8,15.9$, and $8.8 \mathrm{mF}$ $\mathrm{cm}^{-2}$, therefore, the ECSA was determined to be $222.5,345,397.5$ and $220 \mathrm{~cm}^{2}$, respectively.

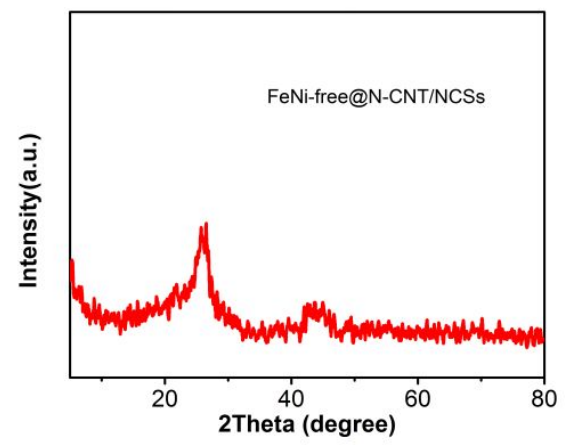

Figure S19. XRD pattern of FeNi-free@N-CNT/NCSs. From this XRD pattern, the typical diffraction peaks related to graphitic carbon are retained. And all the diffraction peaks related to FeNi alloys are disappeared, indicating the most metal species are removed. 


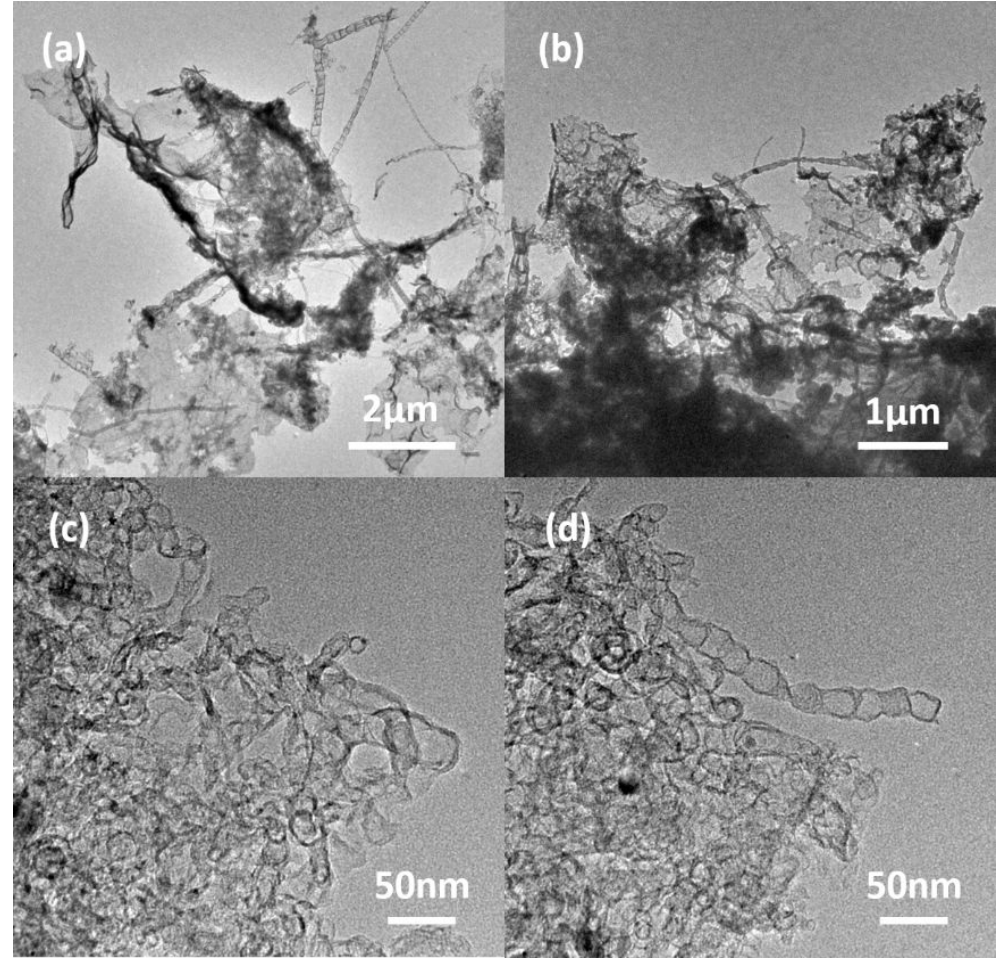

Figure S20. (a-d) TEM images of FeNi-free@N-CNT/NCSs.

As shown on the XRD pattern and TEM images, the morphology comparison before and after acid leaching treatment indicates the metal alloys nanoparticles are nearly removed, whereas the typical hierarchical structure with graphitic carbon are well preserved.
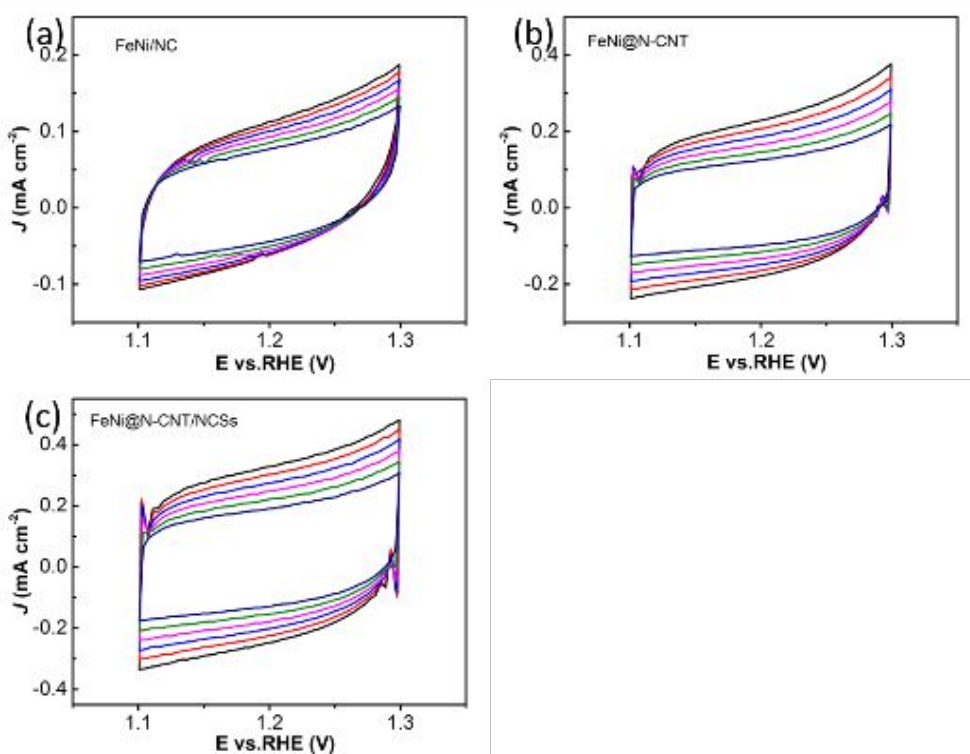

Figure S21. (a-c) Cyclic voltammograms of FeNi/NC, FeNi@N-CNT, and FeNi@N-CNT/NCSs measured at different scan rates from 10 to $20 \mathrm{mV} \mathrm{s}^{-1}$. 


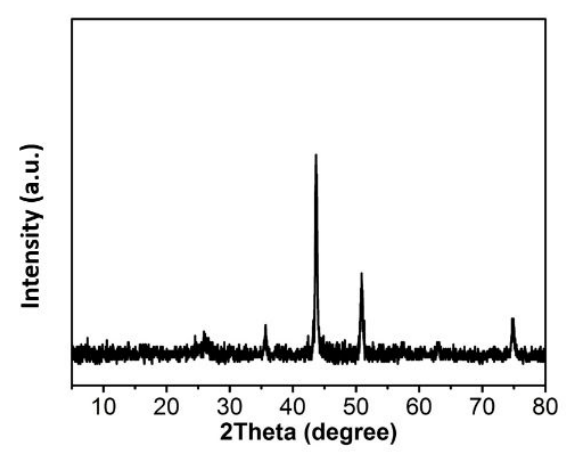

Figure S22. XRD pattern of FeNi@N-CNT/NCSs after long-term OER measurements in $1.0 \mathrm{M}$ $\mathrm{KOH}$.

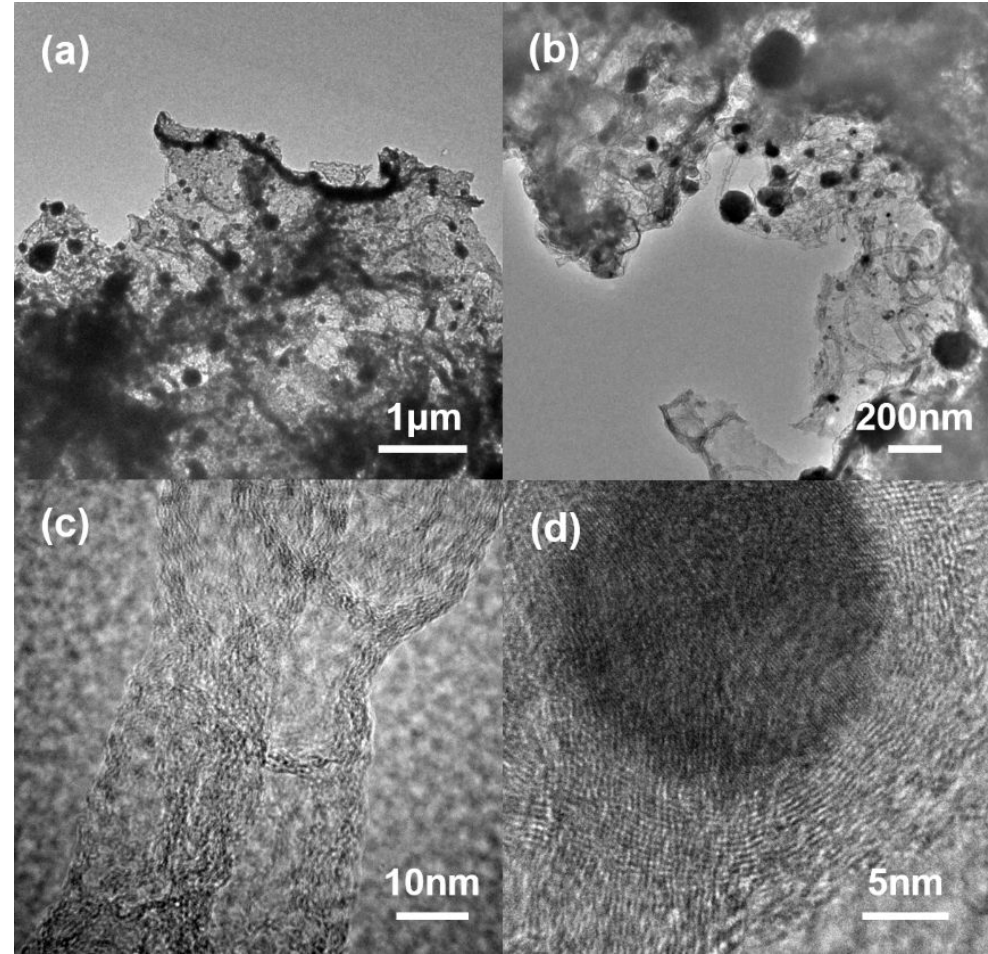

Figure S23. (a-d) TEM images of FeNi@N-CNT/NCSs after long-term OER measurements in 1.0 $\mathrm{M} \mathrm{KOH}$. From the TEM observations, the typical bamboo-like CNTs tangled carbon nanosheets with metal nanoparticles are well maintained after the long-term operation tests. Further magnification on HR-TEM displays the clear graphitic layers ascribed to CNTs, and the observed lattice fringes corresponds to FeNi alloys. Such results indicates the structural robustness for the fabricatedFeNi@N-CNT/NCSs.

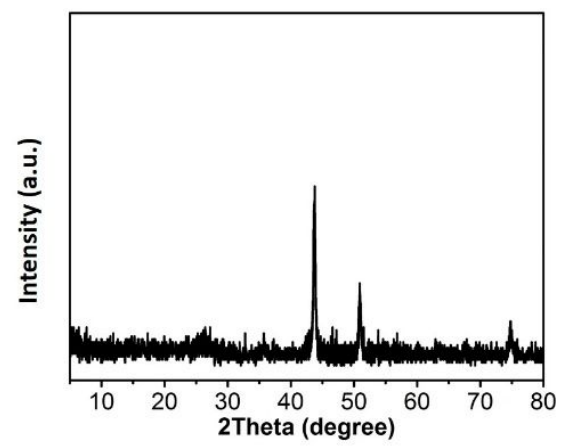


Figure S24. XRD pattern of FeNi@N-CNT/NCSs after long-term HER measurements in $1.0 \mathrm{M}$ $\mathrm{KOH}$.

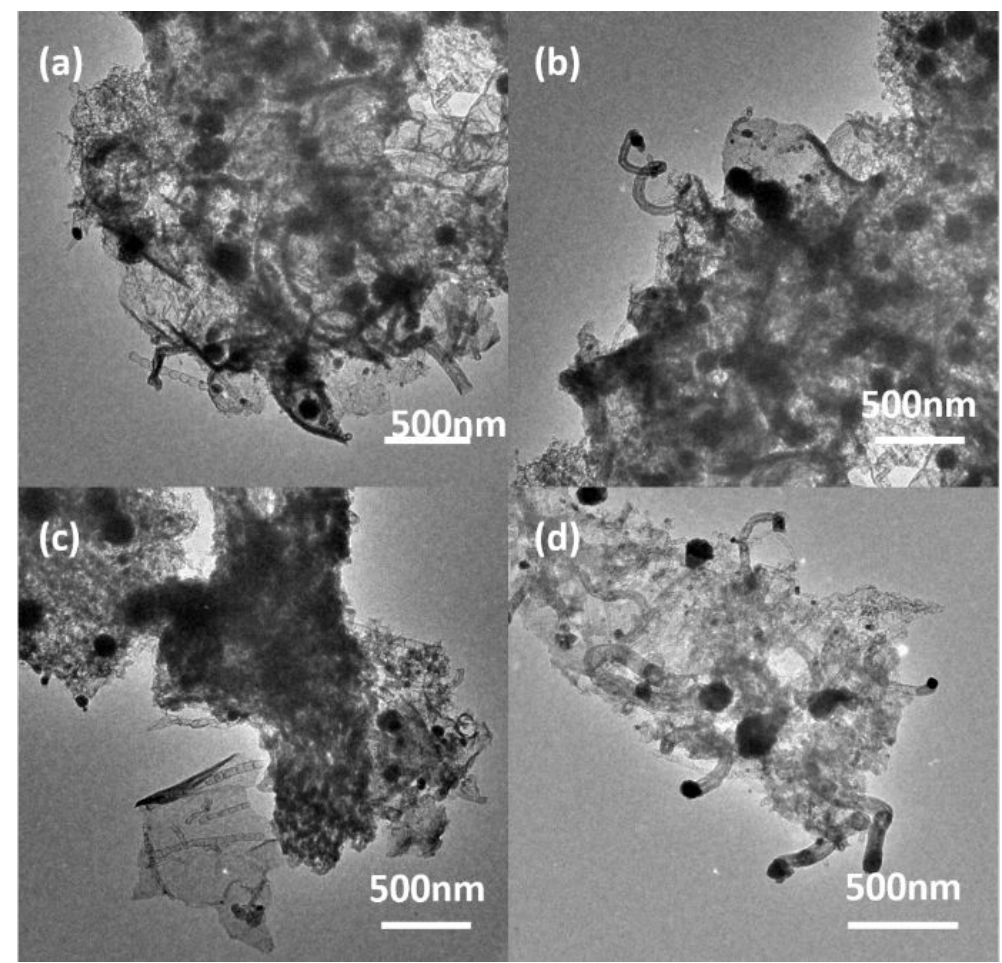

Figure S25. (a-d) TEM images of FeNi@N-CNT/NCSs after long-term HER measurements in 1.0 $\mathrm{M} \mathrm{KOH.}$
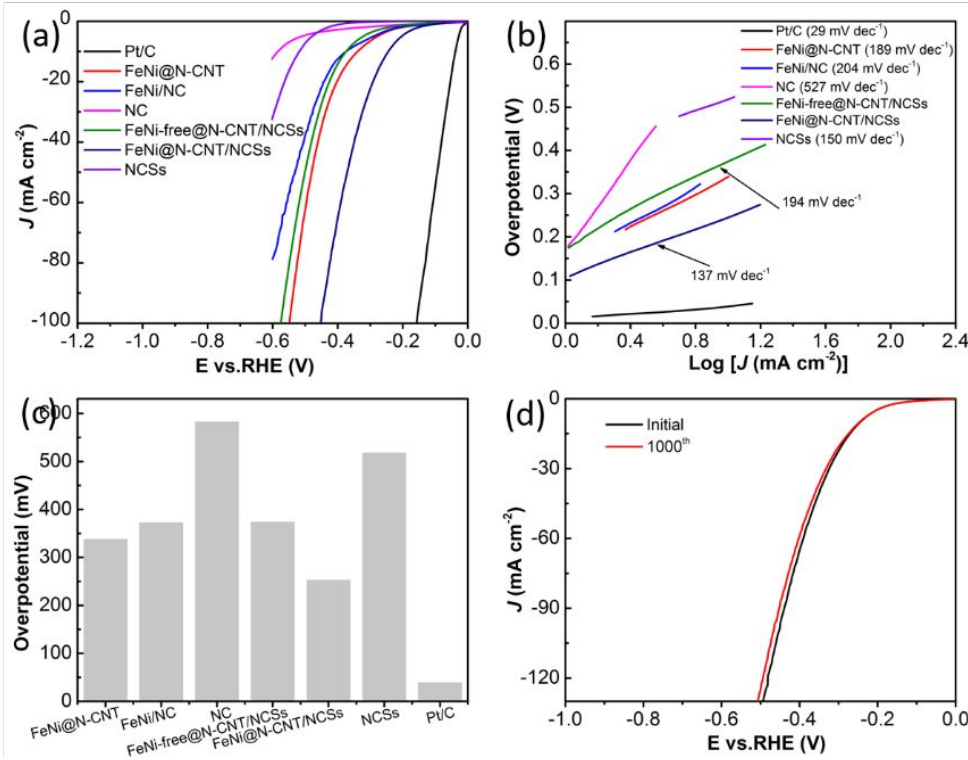

Figure S26. Comparison of HER performances of the fabricated catalysts in $0.5 \mathrm{M} \mathrm{H}_{2} \mathrm{SO}_{4}$. (a) LSV curves. (b) Tafel plots. (c) Comparison of overpotentials at $10 \mathrm{~mA} \mathrm{~cm}{ }^{-2}$. (d) LSV curves of FeNi@N-CNT/NCSs before and after 1000 CV cycles. 


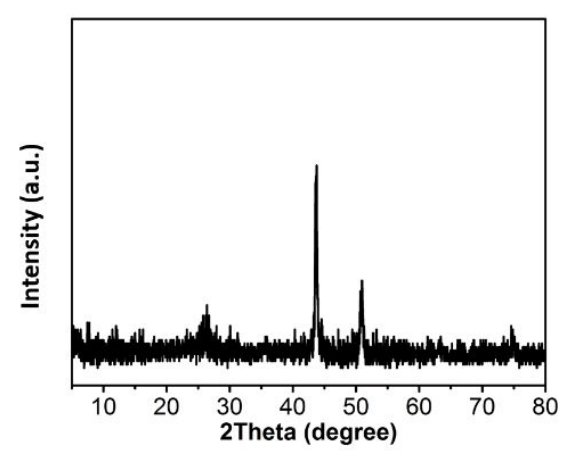

Figure S27. XRD pattern of FeNi@N-CNT/NCSs after long-term HER measurements in $0.5 \mathrm{M}$ $\mathrm{H}_{2} \mathrm{SO}_{4}$.

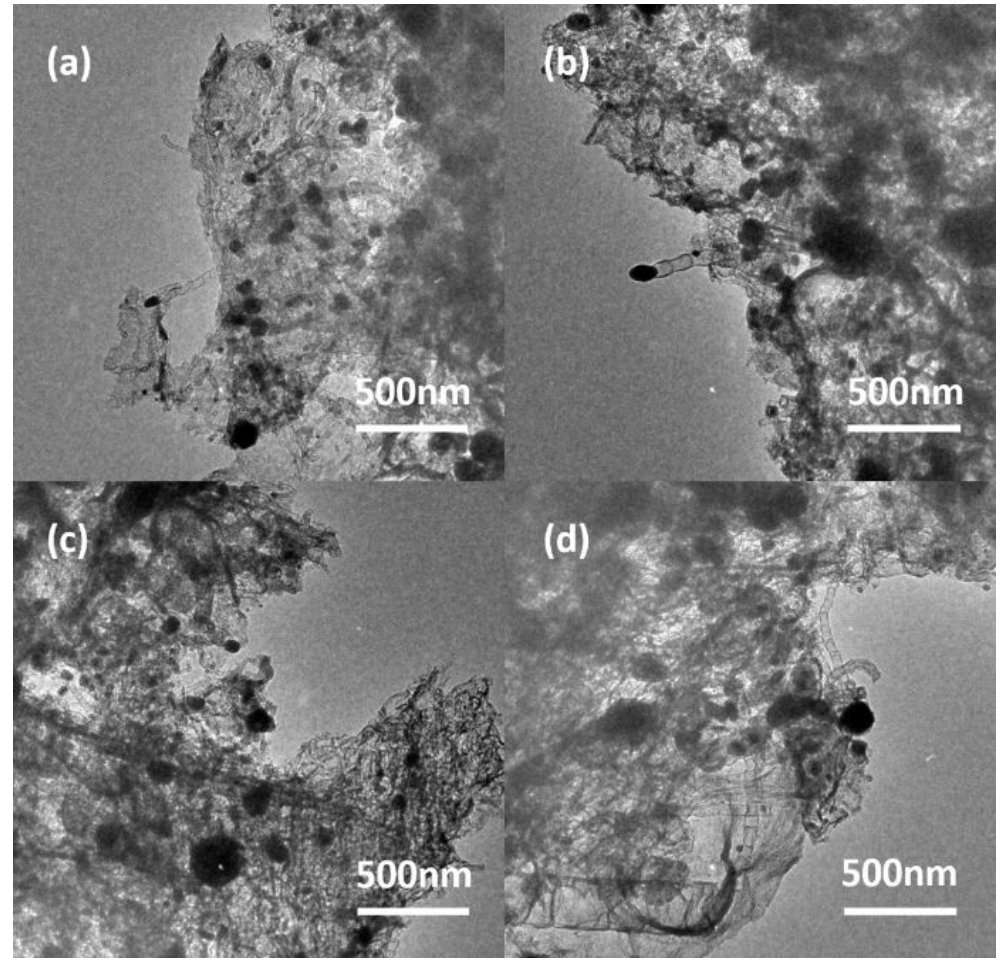

Figure S28. (a-d) TEM images of FeNi@N-CNT/NCSs after long-term HER measurements in 0.5 $\mathrm{M} \mathrm{H}_{2} \mathrm{SO}_{4}$.

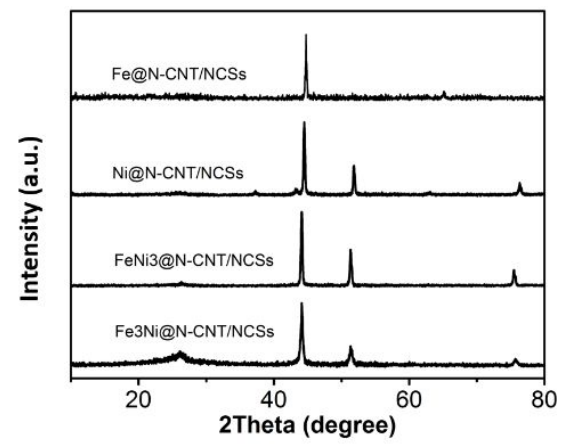

Figure S29. XRD patterns of the developed $\mathrm{Fe}_{\mathrm{x}} \mathrm{Ni}_{\mathrm{y}} @ \mathrm{~N}-\mathrm{CNT} / \mathrm{NCSs}$ with different metal feeding amount. 


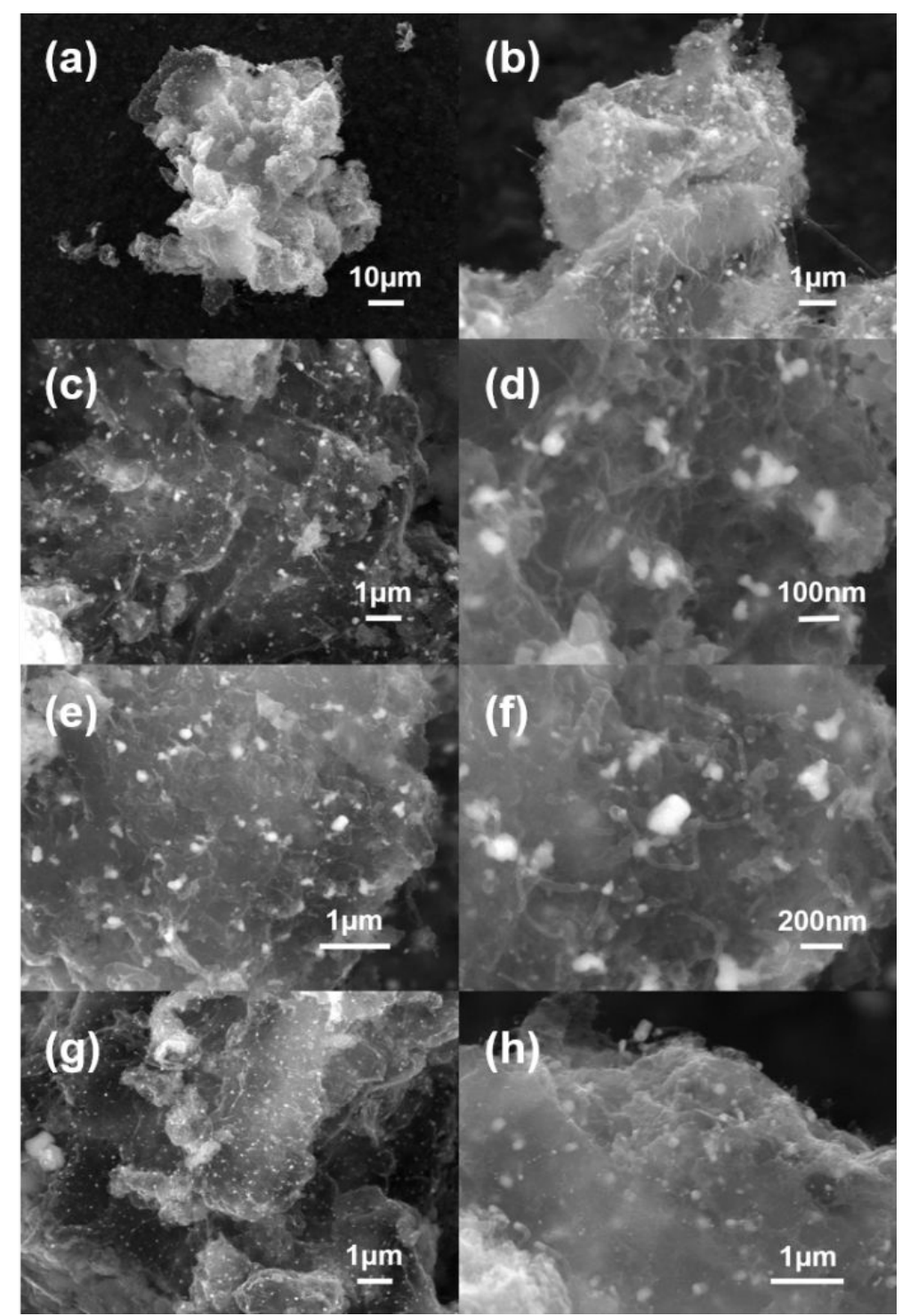

Figure S30. SEM images of Fe@N-CNT/NCSs (a-b), Fe3Ni@N-CNT/NCSs (c-d), FeNi3@NCNT/NCSs (e-f), and Ni@N-CNT/NCSs (g-h).

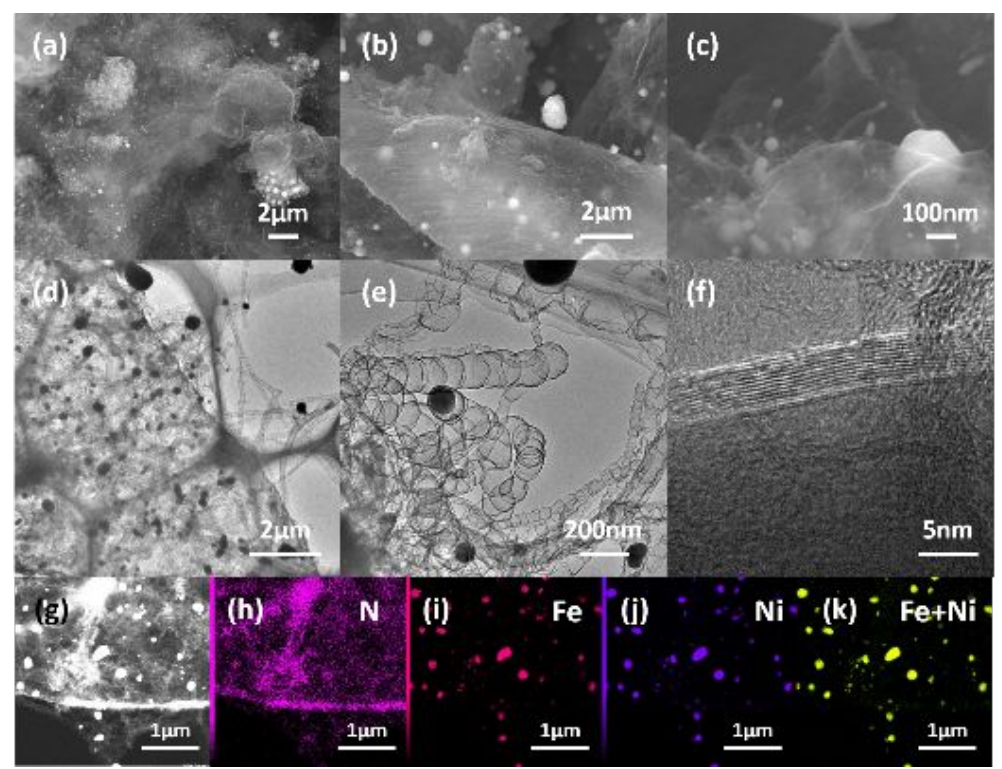


Figure S31. (a-c) SEM, (d-f) TEM images of FeNi3@N-CNT/NCSs. DF-STEM (g) and corresponding EDS images (h-k) of FeNi3@N-CNT/NCSs.

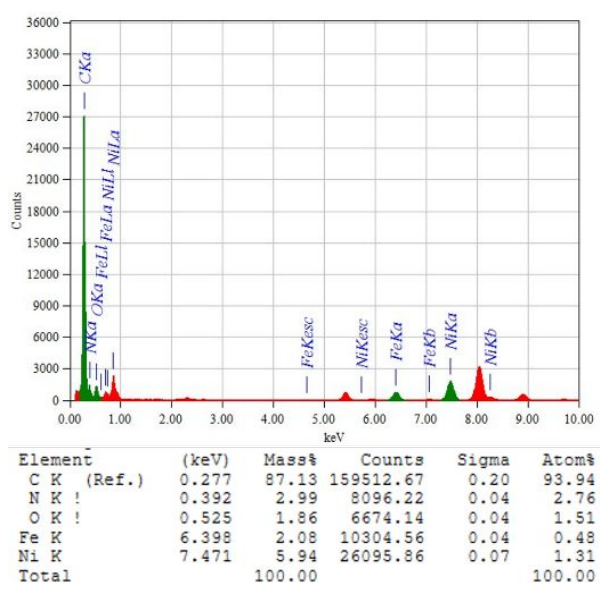

Figure S32. TEM-EDS spectrum of FeNi3@N-CNT/NCSs.
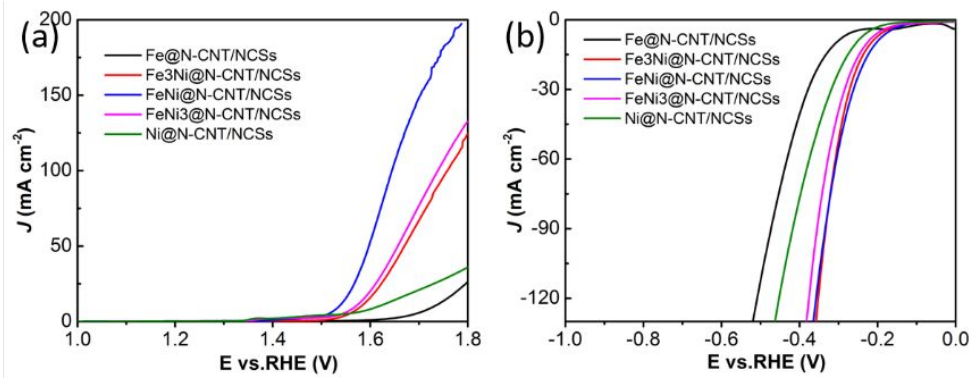

Figure S33. Comparison of OER and HER performances of the fabricated $\mathrm{Fe}_{\mathrm{x}} \mathrm{Ni}_{\mathrm{y}} @ \mathrm{~N}-\mathrm{CNT} / \mathrm{NCSs}$ catalysts in 1.0 M KOH. (a) LSV curves for OER. (b) LSV curves for HER.

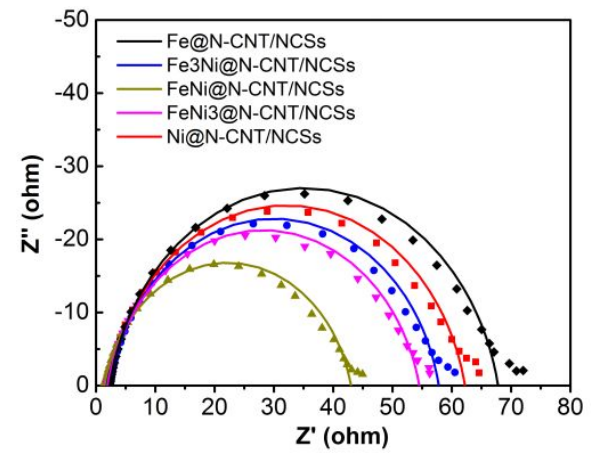

Figure S34. Nyquist plots of the fabricated $\mathrm{Fe}_{\mathrm{x}} \mathrm{Ni}_{\mathrm{y}} @ \mathrm{~N}-\mathrm{CNT} / \mathrm{NCSs}$ catalysts. 

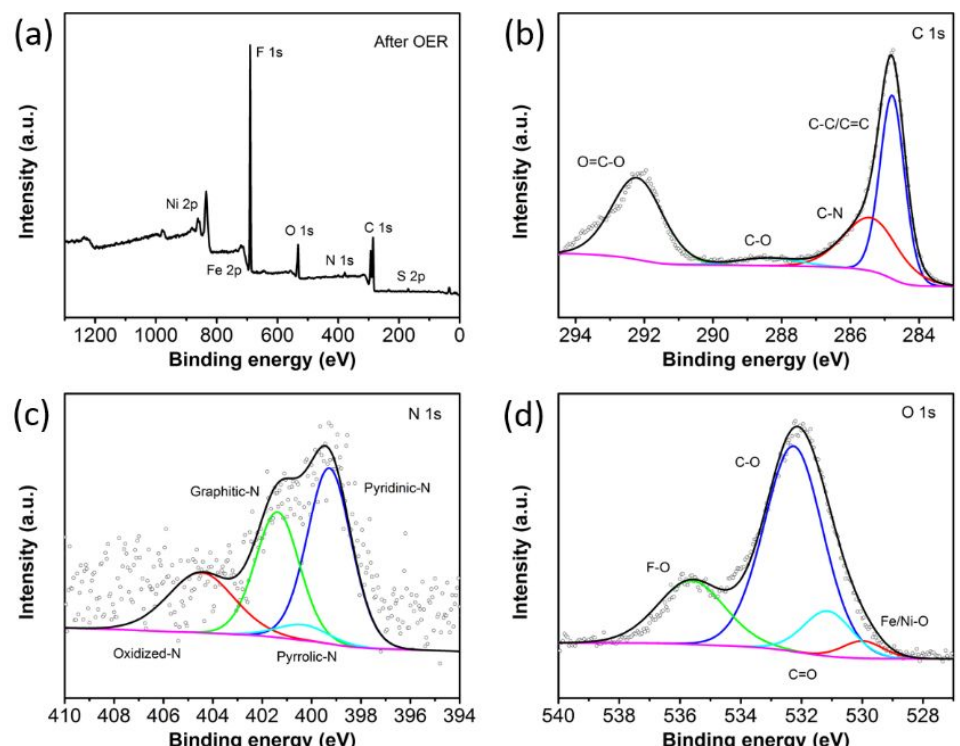

Figure S35. XPS survey spectra (a), C 1s spectra (b), N 1s spectra (c), and O 1s spectra (d) of FeNi@N-CNT/NCSs after OER stability tests in 1.0 M KOH. The XPS survey spectrum of FeNi@N-CNT/NCSs after OER test contains S, C, N, O, F, Fe, and Ni elements. The existence of $\mathrm{S}$ and $\mathrm{F}$ species can be explained by the use of Nafion polymer during the electrode preparation. For $\mathrm{C} 1 \mathrm{~s}$, besides the typical $\mathrm{C}-\mathrm{C} / \mathrm{C}=\mathrm{C}, \mathrm{C}-\mathrm{N}$, and $\mathrm{C}-\mathrm{O}$ contributions, the signal related to $\mathrm{O}=\mathrm{C}-\mathrm{O}$ is significantly raised as compared with the initial one. For $\mathrm{N} \mathrm{1s,} \mathrm{the} \mathrm{components} \mathrm{including}$ pyridinic-N, pyrrolic-N, graphitic-N, and oxidized-N are still reserved. In addition, combining with the typical signal of $\mathrm{Fe} / \mathrm{Ni}-\mathrm{O}$ bonds on $\mathrm{O} 1 \mathrm{~s}$ spectrum, the surface oxidation process is take placed during the long-term oxygen evolution process.
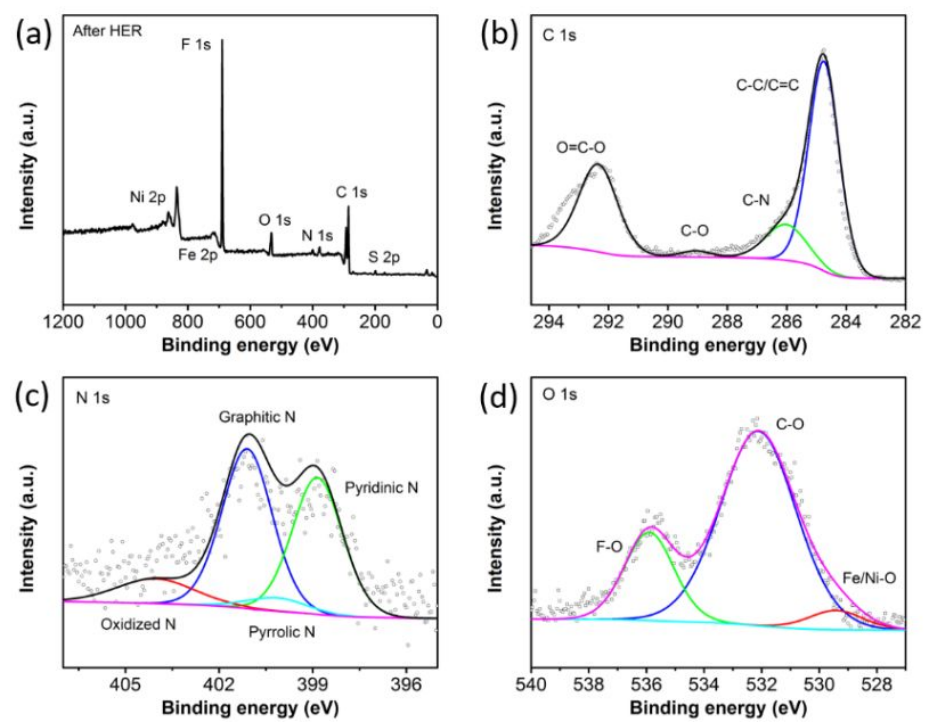

Figure S36. XPS survey spectra (a), C 1s spectra (b), N 1s spectra (c), and O 1s spectra (d) of FeNi@N-CNT/NCSs after HER stability tests in 1.0 M KOH. 


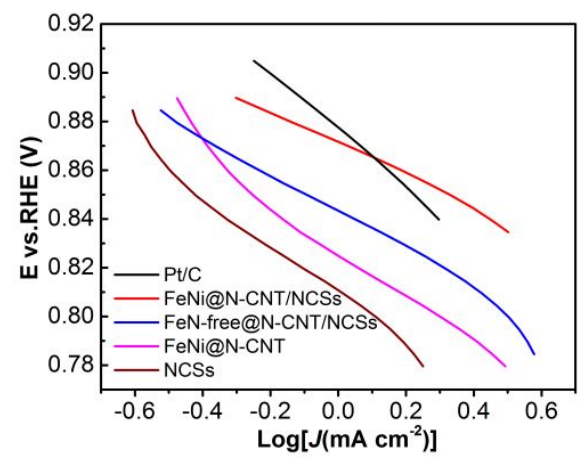

Figure S37. Tafel slopes of those fabricated catalysts in ORR potential region.
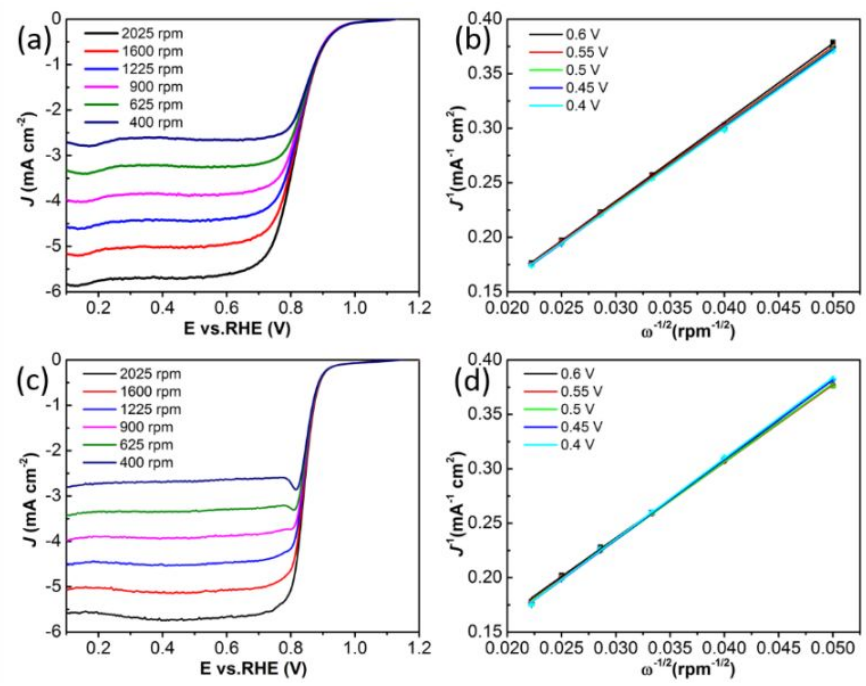

Figure S38. ORR polarization curves of the developed catalysts under various rotating speeds and their corresponding K-L plots at 0.4-0.6 V. (a-b) commercial Pt/C catalyst; (c-d) FeNi@NCNT/NCSs. From the K-L plots, the electron transfer number (n) was calculated to be 3.80-3.98, 3.82-3.96 for Pt/C catalyst and FeNi@N-CNT/NCSs.

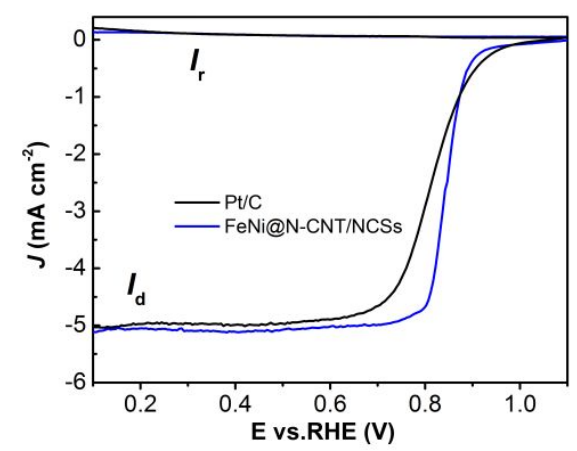

Figure S39. The disk current $\left(I_{\mathrm{d}}\right)$ and ring current $\left(I_{\mathrm{r}}\right)$ of the prepared FeNi@N-CNT/NCSs and commercial $\mathrm{Pt} / \mathrm{C}$ catalysts in the RRDE test. 

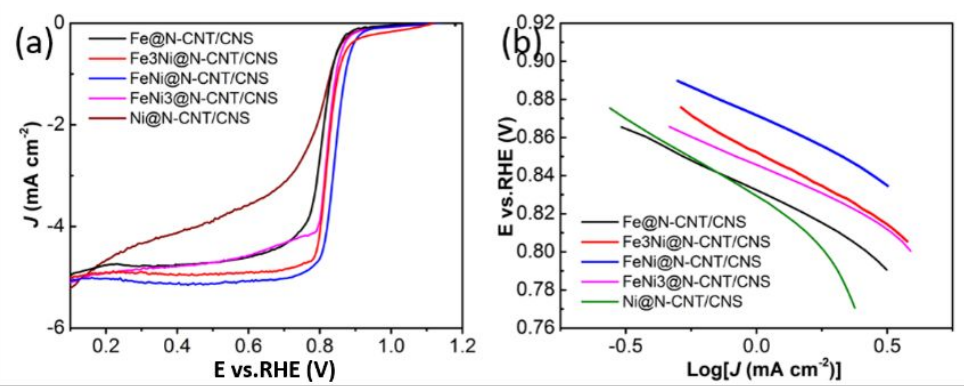

Figure S40. (a) ORR polarization curves of the fabricated $\mathrm{Fe}_{\mathrm{x}} \mathrm{Ni}_{\mathrm{y}} @ \mathrm{~N}-\mathrm{CNT} / \mathrm{NCSs}$ catalysts in $\mathrm{O}_{2^{-}}$ saturated 0.1 M KOH. (b) Tafel plots.

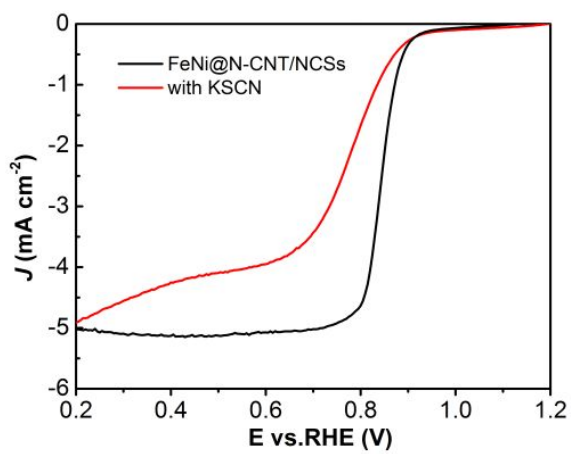

Figure S41. ORR polarization curves of the fabricated $\mathrm{Fe}_{\mathrm{x}} \mathrm{Ni}_{\mathrm{y}} @ \mathrm{~N}-\mathrm{CNT} / \mathrm{NCSs}$ catalyst in $\mathrm{O}_{2^{-}}$ saturated $0.1 \mathrm{M} \mathrm{KOH}$ with the absence or presence of KSCN.
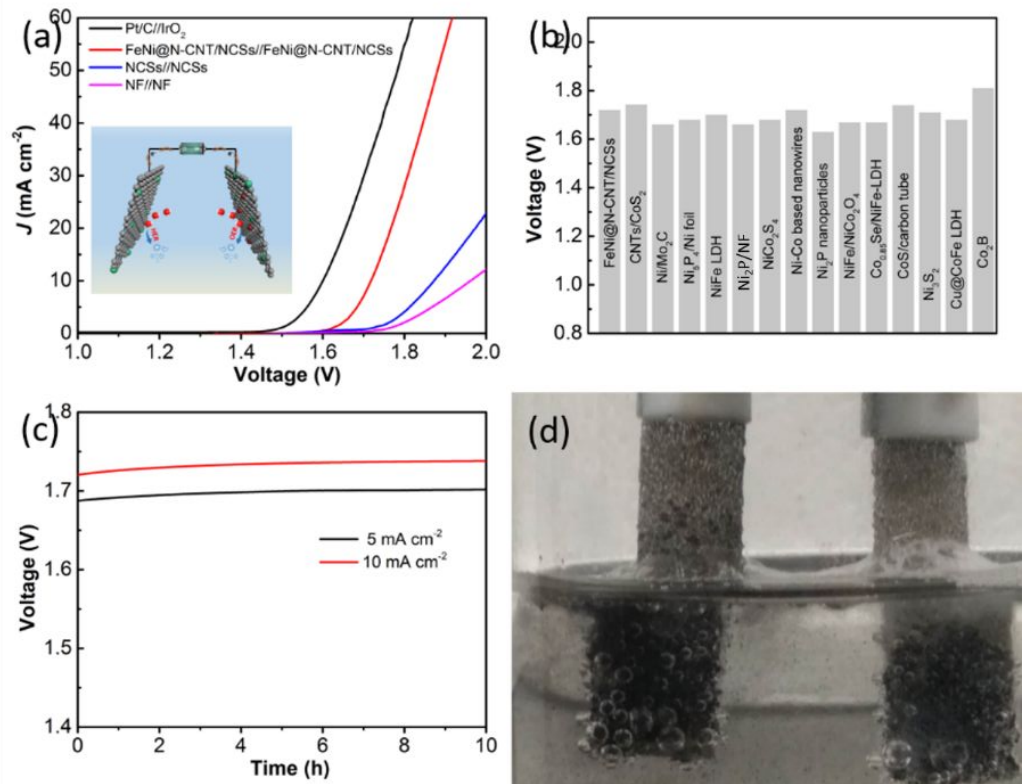

Figure S42. (a) Polarization curves of the two-electrode alkaline electrolyzer with different electrodes. Inset in (a) is the illustration of two-electrode construction with the catalysts coated Ni foam both as anode and cathode. (b) Comparison of the required cell voltage at a current density of $10 \mathrm{~mA} \mathrm{~cm}{ }^{-2}$ for $\mathrm{FeNi} @ \mathrm{~N}-\mathrm{CNT} / \mathrm{NCSs}$ and other recently reported bifunctional catalysts including $\mathrm{CNTs} / \mathrm{CoS}_{2},{ }^{3} \mathrm{Ni} / \mathrm{Mo}_{2} \mathrm{C},{ }^{4} \mathrm{Ni}_{5} \mathrm{P}_{4} / \mathrm{Ni}$ foil, ${ }^{5} \mathrm{NiFe} \mathrm{LDH},{ }^{6} \mathrm{Ni}_{2} \mathrm{P} / \mathrm{NF},{ }^{7} \mathrm{NiCo}_{2} \mathrm{~S}_{4},{ }^{8} \mathrm{Ni}-\mathrm{Co}$ based nanowires, ${ }^{9} \mathrm{Ni}_{2} \mathrm{P}$ nanoparticles, ${ }^{10} \mathrm{NiFe} / \mathrm{NiCO}_{2} \mathrm{O}_{4},{ }^{11} \mathrm{Co}_{0.85} \mathrm{Se} / \mathrm{NiFe}-\mathrm{LDH},{ }^{12} \mathrm{CoS} /$ carbon tube, ${ }^{13}$ $\mathrm{Ni}_{3} \mathrm{~S}_{2},{ }^{14} \mathrm{Cu} @ \mathrm{CoFe} \mathrm{LDH},{ }^{15}$ and $\mathrm{Co}_{2} \mathrm{~B} .{ }^{16}$ (c) Galvanostatic water splitting at stationary current densities of 5 and $10 \mathrm{~mA} \mathrm{~cm}{ }^{-2}$ for FeNi@N-CNT/NCSs//FeNi@N-CNT/NCSs (d) A representative photograph of the system depicting $\mathrm{O}_{2}$ (left) and $\mathrm{H}_{2}$ (right) generation during overall water electrolysis. All measurements were carried out in $1.0 \mathrm{M} \mathrm{KOH}$ electrolyte. 

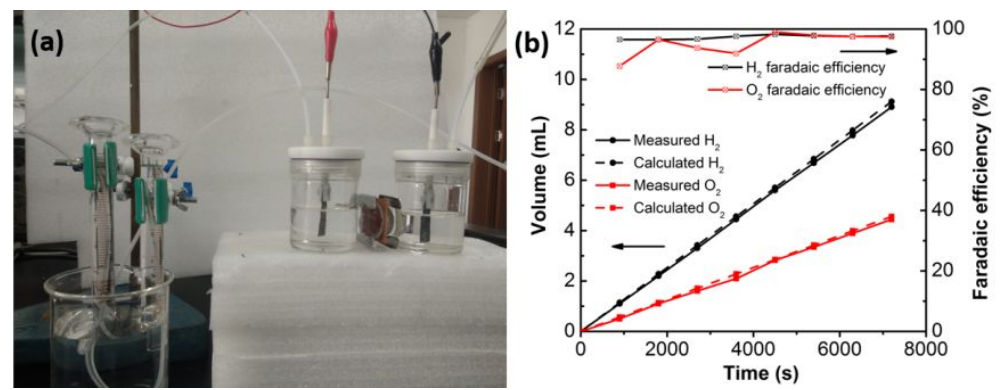

Figure S43. (a) Optical images of the water-gas displacing method for the collection of generated $\mathrm{H}_{2}$ and $\mathrm{O}_{2}$. (b) Experimental and theoretical volumes of $\mathrm{H}_{2}$ and $\mathrm{O}_{2}$ by the FeNi@N-CNT/NCSs electrode in a sealed H-type electrolyzer at a current density of $10 \mathrm{~mA} \mathrm{~cm}^{-2}$, and the corresponding calculated Faradaic efficiency. For the overall water splitting, the FeNi@N-CNT/NCSs coated nickel foam was directly used as both cathodic and anodic electrodes for $\mathrm{H}_{2}$ and $\mathrm{O}_{2}$ production. And the Faradaic efficiency was calculated by evaluating the volume of experimentally quantified gas (water-gas displacing method at the current density of $10 \mathrm{~mA} \mathrm{~cm}$ ) with theoretically calculated gas:

$$
\eta_{\text {Faradaic efficiency }}=\left(\mathrm{V}_{\text {experimental }} / \mathrm{V}_{\text {theoretical }}\right) \times 100 \%
$$

The theoretical volume of evolving gases can be calculated using the equation:

$$
\mathrm{V}_{\text {theoretical }}=\left(\mathrm{I} \times \mathrm{t} \times \mathrm{V}_{\mathrm{m}}\right) /(\mathrm{n} \times \mathrm{F})
$$

where $\mathrm{I}$ is the current measured in the experiment, $\mathrm{t}$ is the recorded time, $\mathrm{V}_{\mathrm{m}}$ is the molar volume of $\mathrm{H}_{2}$ or $\mathrm{O}_{2}$ in $1 \mathrm{moL}^{-1}, \mathrm{n}$ is the number of electrons needed for $1 \mathrm{moL}$ of $\mathrm{H}_{2}$ or $\mathrm{O}_{2}$ and $\mathrm{F}$ is the Faradaic constant $\left(96485 \mathrm{C} \mathrm{moL}^{-1}\right)$.

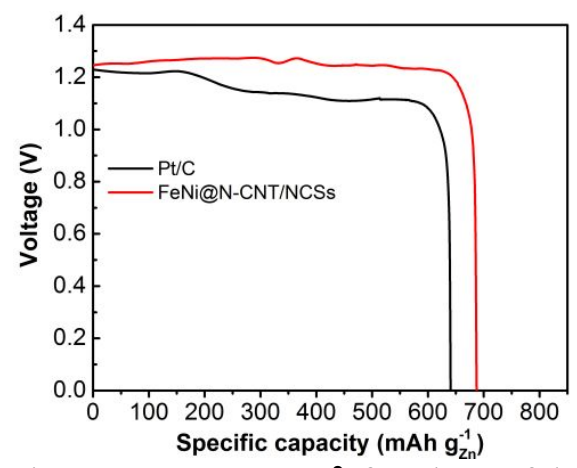

Figure S44. Specific capacity plots at $10 \mathrm{~mA} \mathrm{~cm}^{-2}$ for those fabricated $\mathrm{Zn}$-air batteries from the cathode catalyst of FeNi@N-CNT/NCSs and Pt/C catalyst.

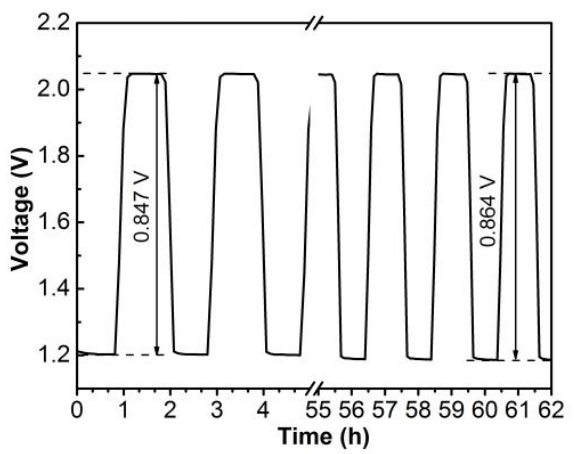

Figure S45. Magnified observation of the galvanostatic charge/discharge cycling curves of FeNi@N-CNT/NCSs fabricated Zn-air battery. 


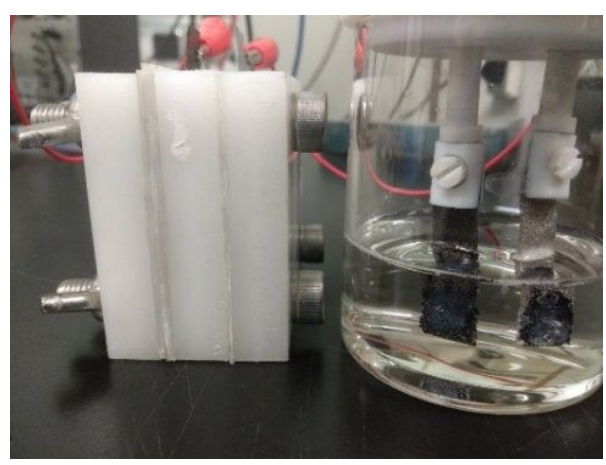

Figure S46. Digital photograph of the FeNi@N-CNT/NCSs fabricated two-electrode overall water splitting configuration powered by liquid Zn-air batteries with the FeNi@N-CNT/NCSs air cathode.

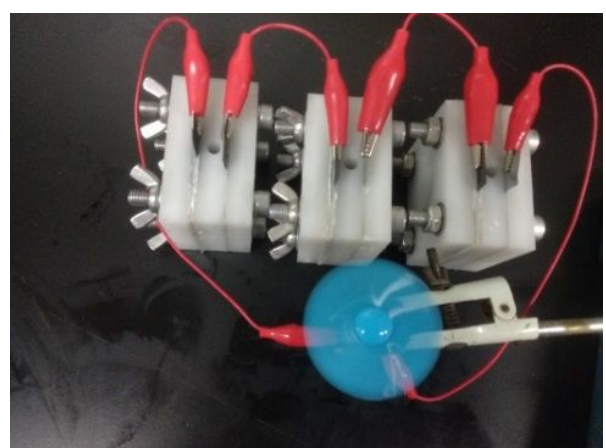

Figure S47. The realistic electronic mini-electric fan powered by three fabricated $\mathrm{Zn}$-air batteries with FeNi@N-CNT/NCSs connected in series. 


\section{Supplementary Tables}

Table S1. The detailed components of the fabricated FeNi@N-CNT/NCSs and NCSs based on XPS analysis.

\begin{tabular}{cccccccccc}
\hline Samples & $\mathrm{C} \mathrm{at} \%$ & $\mathrm{~N} \mathrm{at} \%$ & $\mathrm{O}$ at $\%$ & $\mathrm{Fe}$ at $\%$ & $\mathrm{Ni}$ at $\%$ & pyridinic N \% & pyrrolic N \% & graphitic N \% & Oxidized N \% \\
\hline FeNi@N- & 90.08 & 5.93 & 3.24 & 0.40 & 0.35 & 34.08 & 3.70 & 50.19 \\
CNT/NCSs & & & & & & & & \\
NCSs & 91.35 & 4.68 & 3.97 & - & - & 35.96 & 4.26 & 45.12 \\
\hline
\end{tabular}

Table S2. Comparison of HER and OER performance of the standard FeNi@N-CNT/NCSs with some previously reported non-noble bifunctional catalysts in $1.0 \mathrm{M} \mathrm{KOH}$ solution.

\begin{tabular}{|c|c|c|c|c|c|}
\hline \multirow[b]{2}{*}{ Catalysts } & \multicolumn{2}{|c|}{ HER } & \multicolumn{2}{|c|}{ OER } & \multirow[b]{2}{*}{ Ref. } \\
\hline & @ $10 \mathrm{~mA} \mathrm{~cm}{ }^{-2}(\mathrm{mV})$ & $\begin{array}{c}\text { Tafel slope (mV } \\
\left.\operatorname{dec}^{-1}\right)\end{array}$ & @10 mA cm-2 (mV) & $\begin{array}{c}\text { Tafel slope }(\mathrm{mV} \\
\left.\mathrm{dec}^{-1}\right)\end{array}$ & \\
\hline FeNi@N-CNT/NCS & 203 & 116 & 310 & 71 & This work. \\
\hline $\mathrm{FeS} / \mathrm{Fe}_{3} \mathrm{C} @ \mathrm{~N}-\mathrm{S}-\mathrm{C}-800$ & 446 & N.A. & 570 & 81 & 18 \\
\hline $\mathrm{Co} / \mathrm{CoP}-\mathrm{HNC}$ & 180 & 105.6 & 300 & 44.2 & 19 \\
\hline $\mathrm{Co} / \mathrm{CoP}-5$ & 253 & 73.8 & 340 & 79.5 & 20 \\
\hline CoNiP@LDH-100 NSAs & 83 & 80 & 216 & 45 & 23 \\
\hline NiFe LDH@NiCoP/NF & 120 & 88.2 & 220 & 48.6 & 24 \\
\hline $\mathrm{Fe} 17.5 \%-\mathrm{Ni}_{3} \mathrm{~S}_{2} / \mathrm{NF}$ & 47 & 95 & 214 & 42 & 25 \\
\hline $\mathrm{CoP} / \mathrm{NCNHP}$ & 115 & 66 & 310 & 70 & 26 \\
\hline $\mathrm{FeS}_{2} / \mathrm{CoS}_{2} \mathrm{NSs}$ & 78.2 & 44 & $302 @_{J=100}$ & 42 & 27 \\
\hline $\mathrm{Co}_{9} \mathrm{~S}_{8} @ \mathrm{MoS}_{2}$ & 143 & 117 & 340 & 94 & 28 \\
\hline
\end{tabular}


Table S3. Comparison of ORR and OER performance of the standard FeNi@N-CNT/NCSs with some previously reported non-noble bifunctional catalysts in $0.1 \mathrm{M} \mathrm{KOH}$ solution.

\begin{tabular}{|c|c|c|c|c|c|c|c|}
\hline \multirow[b]{2}{*}{ Catalysts } & \multicolumn{2}{|c|}{ ORR } & \multicolumn{2}{|c|}{ OER } & \multirow{2}{*}{$\begin{array}{c}\text { Catalyst } \\
\text { loading (mg } \\
\left.\mathrm{cm}^{-2}\right)\end{array}$} & \multirow[b]{2}{*}{$\Delta E(\mathrm{~V})$} & \multirow[b]{2}{*}{ Ref. } \\
\hline & $\begin{array}{l}\text { @ half-wave } \\
\text { potential (V) }\end{array}$ & $\begin{array}{l}\text { Tafel slope } \\
\left.(\mathrm{mV} \mathrm{dec})^{-1}\right)\end{array}$ & $\begin{array}{c}\text { (a) } 10 \mathrm{~mA} \mathrm{~cm}^{-2} \\
(\mathrm{~V})\end{array}$ & $\begin{array}{l}\text { Tafel slope } \\
\left(\mathrm{mV} \mathrm{dec} \mathrm{de}^{-1}\right)\end{array}$ & & & \\
\hline $\mathrm{FeNi@N-CNT/NCS}$ & 0.84 & 67 & 1.59 & N.A. & 0.255 & 0.75 & This work. \\
\hline $\mathrm{Pt} / \mathrm{C}$ & 0.90 & N.A. & 1.90 & 354.9 & 0.21 & 1.0 & 33 \\
\hline $\mathrm{IrO}_{2}$ & 0.29 & N.A. & 1.70 & 86.2 & 0.21 & 1.41 & 33 \\
\hline $\mathrm{Co} / \mathrm{NC}$ & 0.83 & N.A. & 1.69 & 125.3 & 0.21 & 0.86 & 33 \\
\hline $\mathrm{Co}_{3} \mathrm{O}_{4} / \mathrm{NPGC}$ & 0.84 & N.A. & 1.68 & N.A. & 0.2 & 0.84 & 36 \\
\hline $\mathrm{Fe} @ \mathrm{~N}-\mathrm{C} 700$ & 0.83 & N.A. & 1.71 & N.A. & 0.31 & 0.88 & 37 \\
\hline CoFe@NCNTs & 0.84 & N.A. & 1.68 & 158 & 0.8 & 0.84 & 38 \\
\hline $\mathrm{Co}-\mathrm{N} / \mathrm{C} 800$ & 0.76 & 61 & 1.74 & 130.2 & 0.24 & 0.98 & 39 \\
\hline $\mathrm{Co}_{3} \mathrm{O}_{4} / \mathrm{NBGHS}$ & 0.86 & 34.4 & 1.71 & 63 & N.A. & 0.85 & 40 \\
\hline $\begin{array}{l}\text { N-doped graphene } \\
\text { mesh }\end{array}$ & 0.77 & N.A. & 1.67 & N.A. & 0.25 & 0.90 & 41 \\
\hline
\end{tabular}


Table S4. Summary of overall water splitting performance of recently reported highly active bifunctional non-noble electrocatalysts in alkaline electrolyte.

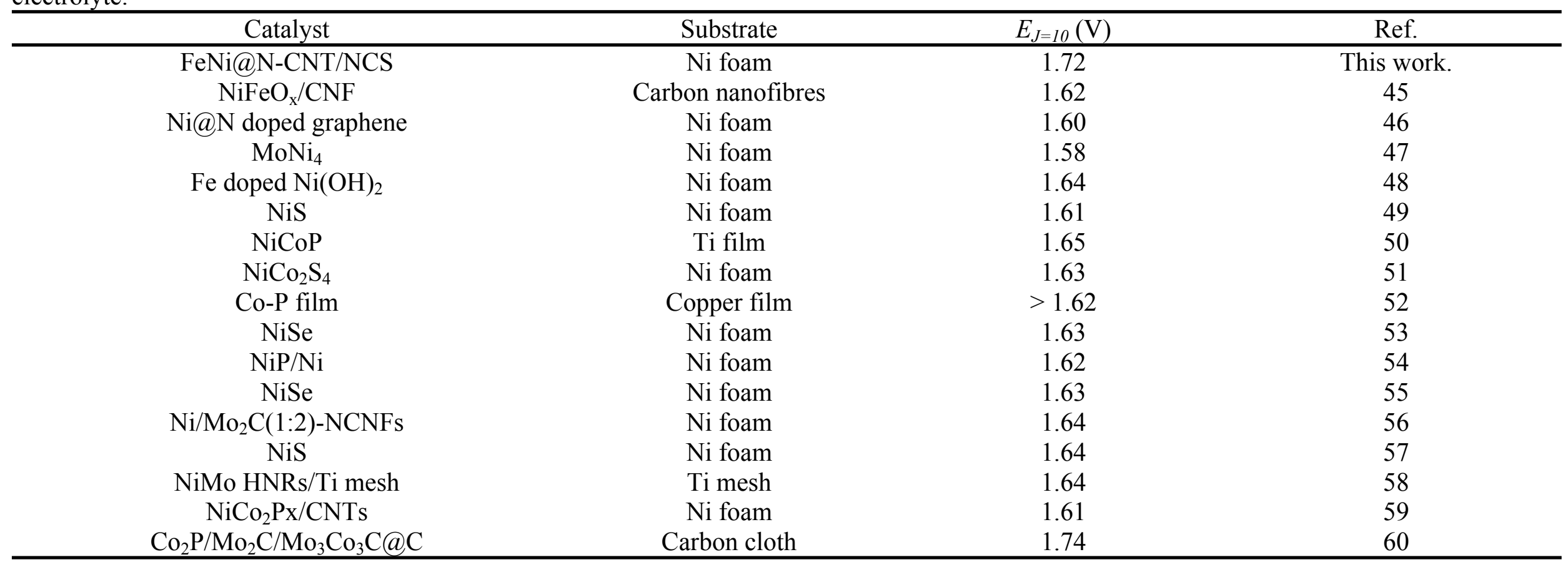


Table S5. The performance comparison of the present reported liquid state rechargeable $\mathrm{Zn}$-air battery.

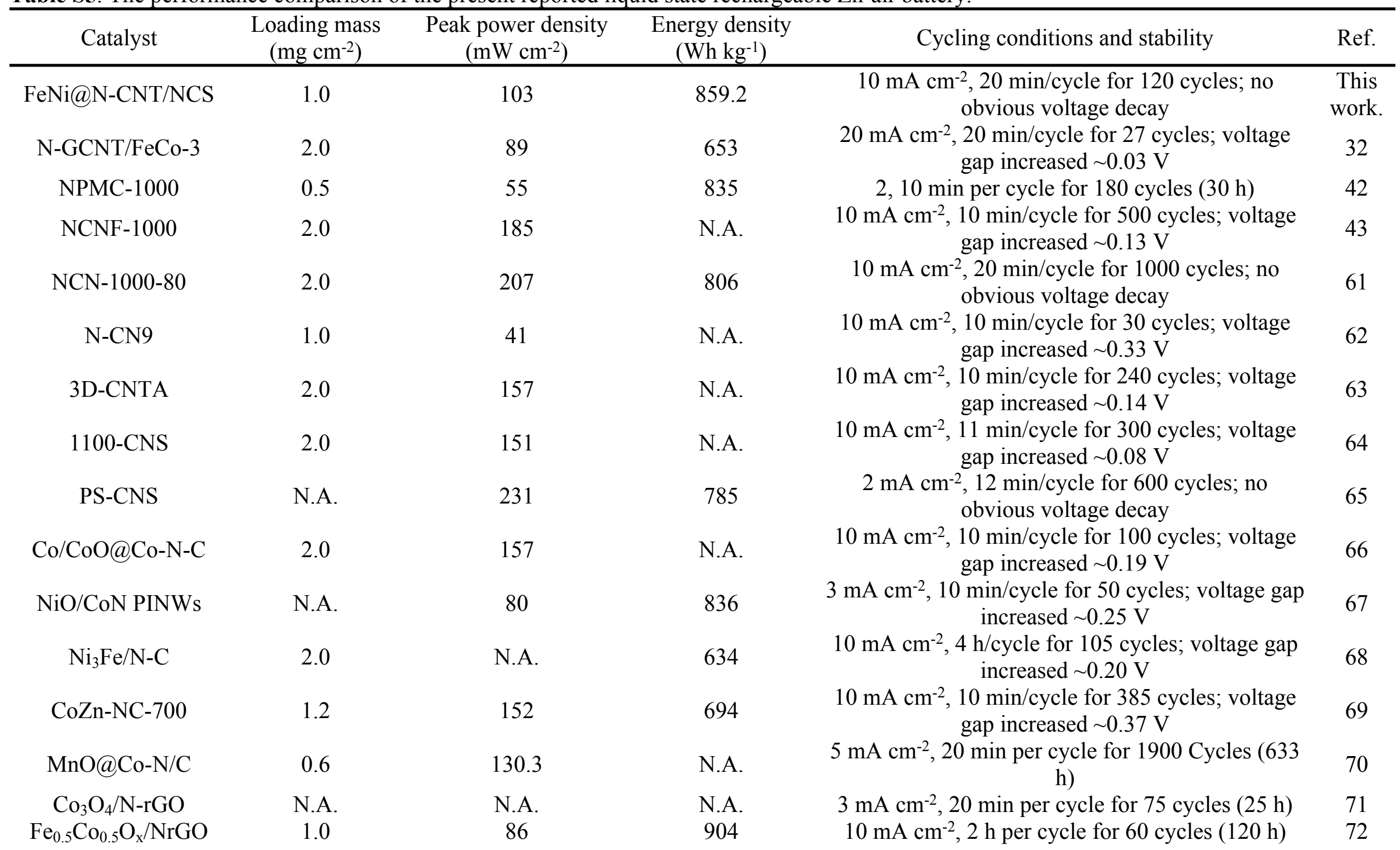




\begin{tabular}{|c|c|c|c|c|c|}
\hline $\mathrm{Co}_{3} \mathrm{FeS}_{1.5}(\mathrm{OH})_{6}$ & 0.5 & 113.1 & N.A. & $2 \mathrm{~mA} \mathrm{~cm}{ }^{-2}, 20 \mathrm{~min}$ per cycle for 108 cycles $(36 \mathrm{~h})$ & 73 \\
\hline $\mathrm{Co}_{3} \mathrm{O}_{4} / \mathrm{N}-\mathrm{CNTAs}$ & 2.0 & N.A. & 734 & $5 \mathrm{~mA} \mathrm{~cm}^{-2}, 10 \mathrm{~min}$ per cycle for 100 cycles $(16.7 \mathrm{~h})$ & 74 \\
\hline $\mathrm{Co}-\mathrm{N}_{\mathrm{x}}-\mathrm{C}$ & 0.50 & 152 & 840 & $2 \mathrm{~mA} \mathrm{~cm}^{-2}, 20 \mathrm{~min}$ per cycle for 180 cycles $(60 \mathrm{~h})$ & 75 \\
\hline $\mathrm{CoS}_{\mathrm{x}} @ \mathrm{PCN} / \mathrm{rGO}$ & 2.0 & N.A. & N.A. & $\begin{array}{c}10 \mathrm{~mA} \mathrm{~cm}^{-2}, 6.6 \mathrm{~min} \text { per cycle for } 394 \text { cycles }(43.8 \\
\mathrm{h})\end{array}$ & 76 \\
\hline $\begin{array}{l}\mathrm{RuO}_{2} \text {-coated } \\
\text { MCNAs }\end{array}$ & $1.5 \sim 2.0$ & N.A. & N.A. & $4 \mathrm{~mA} \mathrm{~cm}^{-2}, 20 \mathrm{~min}$ per cycle for 100 cycles $(34 \mathrm{~h})$ & 77 \\
\hline C-MOF-C2-900 & 0.5 & 105 & N.A. & $10 \mathrm{~mA} \mathrm{~cm}^{-2}, 20 \mathrm{~min}$ per cycle for 90 cycles $(30 \mathrm{~h})$ & 78 \\
\hline
\end{tabular}

\section{Supplementary References}

(1) Wang, X. D.; Xu, Y. F.; Rao, H. S.; Xu, W. J.; Chen, H. Y.; Zhang, W. X.; Kuang, D. B.; Su, C. Y. Novel porous molybdenum tungsten phosphide hybrid nanosheets on carbon cloth for efficient hydrogen evolution. Energy Environ. Sci. 2016, 9, 1468-1475, DOI 10.1039/c5ee03801d.

(2) Tang, C.; Wang, W.; Sun, A.; Qi, C.; Zhang, D.; Wu, Z.; Wang, D. Sulfur Decorated Molybdenum Carbide Catalysts for Enhanced Hydrogen Evolution. ACS Catal. 2015, 5, 6956-6963, DOI 10.1021/acscatal.5b01803.

(3) Wang, J.; Zhong, H. X.; Wang, Z. L.; Meng, F. L.; Zhang, X. B. Integrated three-dimensional carbon paper/carbon tubes/cobalt-sulfide sheets as an efficient electrode for overall water splitting. ACS Nano 2016, 10, 2342-2348, DOI 10.1021/acsnano.5b07126.

(4) Yu, Z. Y.; Duan, Y.; Gao, M. R.; Lang, C. C.; Zheng, Y. R.; Yu, S. H. A one-dimensional porous carbon-supported Ni/Mo $2 \mathrm{C}$ dual catalyst for efficient water splitting. Chem. Sci. 2017, 8, 968-973, DOI 10.1039/C6SC03356C.

(5) Ledendecker, M.; Krick Calderon, S.; Papp, C.; Steinruck, H. P.; Antonietti, M.; Shalom, M. The synthesis of nanostructured Ni $\mathrm{P}_{4}$ films and their use as a non-noble bifunctional electrocatalyst for full water splitting. Angew. Chem. Int. Ed. 2015, 54, 12361-12365, DOI 10.1002/anie.201502438.

(6) Luo, J.; Im, J. H.; Mayer, M. T.; Schreier, M.; Nazeeruddin, M. K.; Park, N. G.; Tilley, S. D.; Fan, H. J.; Grätzel, M. Water photolysis at 12.3\% efficiency via perovskite photovoltaics and Earth-abundant catalysts. Science 2014, 345, 1593-1596, DOI 10.1126/science.1258307.

(7) Ren, J. T.; Hu, Z. P.; Chen, C.; Liu, Y. P.; Yuan, Z. Y. Integrated $\mathrm{Ni}_{2} \mathrm{P}$ nanosheet arrays on three-dimensional Ni foam for highly efficient water reduction and oxidation. J. Energy Chem. 2017, 26, 1196-1202, DOI 10.1016/j.jechem.2017.07.016.

(8) Wang, F. F.; Wei, P. J.; Yu, G. Q.; Liu, J. G. Titanium Dioxide-Grafted Copper Complexes: High-Performance Electrocatalysts for the Oxygen Reduction Reaction in Alkaline Media. Chem. Eur. J. 2015, 22, 382-389, DOI 10.1002/chem. 201502589.

(9) Peng, Z.; Jia, D.; Al-Enizi, A. M.; Elzatahry, A. A.; Zheng, G. From Water Oxidation to Reduction: Homologous Ni-Co Based Nanowires as Complementary Water Splitting Electrocatalysts. Adv. Energy Mater. 2015, 5, 1402031, DOI 10.1002/aenm.201402031.

(10) Stern, L. A.; Feng, L.; Song, F.; Hu, X. $\mathrm{Ni}_{2} \mathrm{P}$ as a Janus catalyst for water splitting: the oxygen evolution activity of $\mathrm{Ni}_{2} \mathrm{P}$ nanoparticles. Energy Environ. Sci. 2015, 8, 2347-2351, DOI 10.1039/C5EE01155H. 
(11) Xiao, C.; Li, Y.; Lu, X.; Zhao, C. Bifunctional Porous NiFe/ $\mathrm{NiCo}_{2} \mathrm{O}_{4} / \mathrm{Ni}$ Foam Electrodes with Triple Hierarchy and Double Synergies for Efficient Whole Cell Water Splitting. Adv. Funct. Mater. 2016, 26, 3515-3523, DOI 10.1002/adfm.201505302.

(12) Hou, Y.; Lohe, M. R.; Zhang, J.; Liu, S.; Zhuang, X.; Feng, X. Vertically oriented cobalt selenide/NiFe layered-double-hydroxide nanosheets supported on exfoliated graphene foil: an efficient 3D electrode for overall water splitting. Energy Environ. Sci. 2016, 9, 478-483, DOI 10.1039/C5EE03440J.

(13) Wang, J.; Zhong, H. X.; Wang, Z. L.; Meng, F. L.; Zhang, X. B. Integrated Three-Dimensional Carbon Paper/Carbon Tubes/Cobalt-Sulfide Sheets as an Efficient Electrode for Overall Water Splitting. ACS Nano 2016, 10, 2342-2348, DOI 10.1021/acsnano.5b07126..

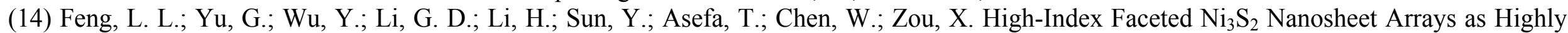
Active and Ultrastable Electrocatalysts for Water Splitting. J. Am. Chem. Soc. 2015, 137, 14023-14026, DOI 10.1021/jacs.5b08186.

(15) Yu, L.; Zhou, H.; Sun, J.; Qin, F.; Luo, D.; Xie, L.; Yu, F.; Bao, J.; Li, Y.; Yu, Y.; Chen, S.; Ren, Z. Hierarchical Cu@CoFe layered double hydroxide core-shell nanoarchitectures as bifunctional electrocatalysts for efficient overall water splitting. Nano Energy 2017, 41, 327-336, DOI 10.1016/j.nanoen.2017.09.045.

(16) Masa, J.; Weide, P.; Peeters, D.; Sinev, I.; Xia, W.; Sun, Z.; Somsen, C.; Muhler, M.; Schuhmann, W. Amorphous Cobalt Boride (Co 2 B) as a Highly Efficient Nonprecious Catalyst for Electrochemical Water Splitting: Oxygen and Hydrogen Evolution. Adv. Energy Mater. 2016, 6, 1502313, DOI 10.1002/aenm.201502313

(17) Yang, Z.; Zhao, C.; Qu, Y.; Zhou, H.; Zhou, F.; Wang, J.; Wu, Y.; Li, Y. Trifunctional Self-Supporting Cobalt-Embedded Carbon Nanotube Films for ORR, OER, and HER Triggered by Solid Diffusion from Bulk Metal. Adv. Mater. 2019, 31, 1808043, DOI 10.1002/adma.201808043.

(18) Kong, F.; Fan, X.; Kong, A.; Zhou, Z.; Zhang, X.; Shan, Y. Covalent Phenanthroline Framework Derived FeS@Fe 3 C Composite Nanoparticles Embedding in N - S - Codoped Carbons as Highly Efficient Trifunctional Electrocatalysts. Adv. Funct. Mater. 2018, 28, 1803973, DOI 10.1002/adfm.201803973.

(19) Hao, Y.; Xu, Y.; Liu, W.; Sun, X. Co/CoP embedded in a hairy nitrogen-doped carbon polyhedron as an advanced tri-functional electrocatalyst. Mater. Horiz. 2018, 5, 108-115, DOI 10.1039/c7mh00706j.

(20) Xue, Z. H.; Su, H.; Yu, Q. Y.; Zhang, B.; Wang, H. H.; Li, X. H.; Chen, J. S. Janus Co/CoP Nanoparticles as Efficient Mott-Schottky Electrocatalysts for Overall Water Splitting in Wide pH Range. Adv. Energy Mater. 2017, 7, 1602355, DOI 10.1002/aenm.201602355.

(21) Ahn, S. H.; Manthiram, A. Direct growth of ternary Ni-Fe-P porous nanorods onto nickel foam as a highly active, robust bi-functional electrocatalyst for overall water splitting. J. Mater. Chem. A 2017, 5, 2496-2503, DOI 10.1039/C6TA10509B.

(22) Yang, R.; Zhou, Y.; Xing, Y.; Li, D.; Jiang, D.; Chen, M.; Shi, W.; Yuan, S. Synergistic coupling of CoFe-LDH arrays with NiFe-LDH nanosheet for highly efficient overall water splitting in alkaline media. Appl. Catal. B: Environ. 2019, 253, 131-139, DOI 10.1016/j.apcatb.2019.04.054.

(23) Zhou, L.; Jiang, S.; Liu, Y.; Shao, M.; Wei, M.; Duan, X. Ultrathin CoNiP@Layered Double Hydroxides Core-Shell Nanosheets Arrays for Largely Enhanced Overall Water Splitting. ACS Appl. Energy Mater. 2018, 1, 623-631, DOI 10.1021/acsaem.7b00151. 
(24) Zhang, H.; Li, X.; Hähnel, A.; Naumann, V.; Lin, C.; Azimi, S.; Schweizer, S. L.; Maijenburg, A. W.; Wehrspohn, R. B. Bifunctional Heterostructure Assembly of NiFe LDH Nanosheets on NiCoP Nanowires for Highly Efficient and Stable Overall Water Splitting. Adv. Funct. Mater. 2018, 28, 1706847, DOI 10.1002/adfm.201706847.

(25) Zhang, G.; Feng, Y. S.; Lu, W. T.; He, D.; Wang, C. Y.; Li, Y. K.; Wang, X. Y.; Cao, F. F. Enhanced Catalysis of Electrochemical Overall Water Splitting in Alkaline Media by Fe Doping in $\mathrm{Ni}_{3} \mathrm{~S}_{2}$ Nanosheet Arrays. ACS Catal. 2018, 8, 5431-5441, DOI 10.1021/acscatal.8b00413.

(26) Pan, Y.; Sun, K.; Liu, S.; Cao, X.; Wu, K.; Cheong, W. C.; Chen, Z.; Wang, Y.; Li, Y.; Liu, Y.; Wang, D.; Peng, Q.; Chen, C.; Li, Y. Core-Shell ZIF-8@ZIF-67-Derived CoP Nanoparticle-Embedded N-Doped Carbon Nanotube Hollow Polyhedron for Efficient Overall Water Splitting. J. Am. Chem. Soc. 2018, 140, 2610-2618, DOI 10.1021/jacs.7b12420.

(27) Li, Y.; Yin, J.; An, L.; Lu, M.; Sun, K.; Zhao, Y. Q.; Gao, D.; Cheng, F.; Xi, P. FeS $2 / \mathrm{CoS}_{2}$ Interface Nanosheets as Efficient Bifunctional Electrocatalyst for Overall Water Splitting. Small 2018, 14, 1801070, DOI 10.1002/smll.201801070.

(28) Bai, J.; Meng, T.; Guo, D.; Wang, S.; Mao, B.; Cao, M. Co $9 \mathrm{~S}_{8} @ \mathrm{MoS}_{2}$ Core-Shell Heterostructures as Trifunctional Electrocatalysts for Overall Water Splitting and Zn-Air Batteries. ACS Appl. Mater. Interfaces 2018, 10, 1678-1689, DOI 10.1021/acsami.7b14997.

(29) Yang, J.; Wang, X.; Li, B.; Ma, L.; Shi, L.; Xiong, Y.; Xu, H. Novel Iron/Cobalt-Containing Polypyrrole Hydrogel-Derived Trifunctional Electrocatalyst for Self-Powered Overall Water Splitting. Adv. Funct. Mater. 2017, 27, 1606497, DOI 10.1002/adfm.201606497..

(30) Xu, Y.; Tu, W.; Zhang, B.; Yin, S.; Huang, Y.; Kraft, M.; Xu, R. Nickel Nanoparticles Encapsulated in Few-Layer Nitrogen-Doped Graphene Derived from Metal-Organic Frameworks as Efficient Bifunctional Electrocatalysts for Overall Water Splitting. Adv. Mater. 2017, 29, 1605957, DOI 10.1002/adma.201605957.

(31) Xin, Y.; Kan, X.; Gan, L. Y.; Zhang, Z. Heterogeneous Bimetallic Phosphide/Sulfide Nanocomposite for Efficient Solar-Energy-Driven Overall Water Splitting. ACS Nano 2017, 11, 10303-10312, DOI 10.1021/acsnano.7b05020.

(32) Su, C. Y.; Cheng, H.; Li, W.; Liu, Z. Q.; Li, N.; Hou, Z.; Bai, F. Q.; Zhang, H. X.; Ma, T. Y. Atomic Modulation of FeCo-Nitrogen-Carbon Bifunctional Oxygen Electrodes for Rechargeable and Flexible All-Solid-State Zinc-Air Battery. Adv. Energy Mater. 2017, 7, 1602420 DOI 10.1002/aenm.201602420..

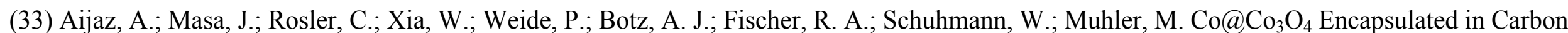
Nanotube-Grafted Nitrogen-Doped Carbon Polyhedra as an Advanced Bifunctional Oxygen Electrode. Angew. Chem. Int. Ed. 2016, 55, 4087-4091, DOI 10.1002/anie.201509382.

(34) Su, C.; Yang, T.; Zhou, W.; Wang, W.; Xu, X.; Shao, Z. Pt/C-LiCoO 2 composites with ultralow Pt loadings as synergistic bifunctional electrocatalysts for oxygen reduction and evolution reactions. J. Mater. Chem. A 2016, 4, 4516-4524, DOI 10.1039/c5ta10492k.

(35) Han, X.; Cheng, F.; Zhang, T.; Yang, J.; Hu, Y.; Chen, J. Hydrogenated uniform Pt clusters supported on porous CaMnO(3) as a bifunctional electrocatalyst for enhanced oxygen reduction and evolution. Adv. Mater. 2014, 26, 2047-2051, DOI 10.1002/adma.201304867.

(36) Li, G.; Wang, X.; Fu, J.; Li, J.; Park, M. G.; Zhang, Y.; Lui, G.; Chen, Z. Pomegranate-Inspired Design of Highly Active and Durable Bifunctional Electrocatalysts for Rechargeable Metal-Air Batteries. Angew. Chem. Int. Ed. 2016, 55, 4977-4982, DOI 10.1002/anie.201600750. 
(37) Wang, J.; Wu, H.; Gao, D.; Miao, S.; Wang, G.; Bao, X. High-density iron nanoparticles encapsulated within nitrogen-doped carbon nanoshell as efficient oxygen electrocatalyst for zinc-air battery. Nano Energy 2015, 13, 387-396, DOI 10.1016/j.nanoen.2015.02.025.

(38) Cai, P.; Hong, Y.; Ci, S.; Wen, Z. In situ integration of CoFe alloy nanoparticles with nitrogen-doped carbon nanotubes as advanced bifunctional cathode catalysts for Zn-air batteries. Nanoscale 2016, 8, 20048-20055, DOI 10.1039/c6nr08057j.

(39) Hu, W.; Wang, Q.; Wu, S.; Huang, Y. Facile one-pot synthesis of a nitrogen-doped mesoporous carbon architecture with cobalt oxides encapsulated in graphitic layers as a robust bicatalyst for oxygen reduction and evolution reactions. J. Mater. Chem. A 2016, 4, 16920-16927, DOI $10.1039 / \mathrm{c} 6 \mathrm{ta} 08103 \mathrm{~g}$.

(40) Jiang, Z.; Jiang, Z. J.; Maiyalagan, T.; Manthiram, A. Cobalt oxide-coated N- and B-doped graphene hollow spheres as bifunctional electrocatalysts for oxygen reduction and oxygen evolution reactions. J. Mater. Chem. A 2016, 4, 5877-5889, DOI 10.1039/c6ta01349j.

(41) Tang, C.; Wang, H. F.; Chen, X.; Li, B. Q.; Hou, T. Z.; Zhang, B.; Zhang, Q.; Titirici, M. M.; Wei, F. Topological Defects in Metal-Free Nanocarbon for Oxygen Electrocatalysis. Adv. Mater. 2016, 28, 6845-6851, DOI 10.1002/adma.201601406.

(42) Zhang, J.; Zhao, Z.; Xia, Z.; Dai, L. A metal-free bifunctional electrocatalyst for oxygen reduction and oxygen evolution reactions. Nat. Nanotech. 2015, 10, 444-452, DOI 10.1038/nnano.2015.48.

(43) Liu, Q.; Wang, Y.; Dai, L.; Yao, J. Scalable Fabrication of Nanoporous Carbon Fiber Films as Bifunctional Catalytic Electrodes for Flexible ZnAir Batteries. Adv. Mater. 2016, 28, 3000-3006, DOI 10.1002/adma.201506112.

(44) Song, J.; Zhu, C.; Fu, S.; Song, Y.; Du, D.; Lin, Y. Optimization of cobalt/nitrogen embedded carbon nanotubes as an efficient bifunctional oxygen electrode for rechargeable zinc-air batteries. J. Mater. Chem. A 2016, 4, 4864-4870, DOI 10.1039/c6ta00615a.

(45) Wang, H.; Lee, H. W.; Deng, Y.; Lu, Z.; Hsu, P. C.; Liu, Y.; Lin, D.; Cui, Y. Bifunctional non-noble metal oxide nanoparticle electrocatalysts through lithium-induced conversion for overall water splitting. Nat. Commun. 2015, 6, 7261, DOI 10.1038/ncomms8261.

(46) Xu, Y.; Tu, W.; Zhang, B.; Yin, S.; Huang, Y.; Kraft, M.; Xu, R. Nickel Nanoparticles Encapsulated in Few - Layer Nitrogen - Doped Graphene Derived from Metal-Organic Frameworks as Efficient Bifunctional Electrocatalysts for Overall Water Splitting. Adv. Mater. 2017, 29, 1605957, DOI 10.1002/adma.201605957.

(47) Jin, Y.; Yue, X.; Shu, C.; Huang, S.; Shen, P. K. Three-dimensional porous MoNi4 networks constructed by nanosheets as bifunctional electrocatalysts for overall water splitting. J. Mater. Chem. A 2017, 5, 2508-2513, DOI 10.1039/C6TA10802D.

(48) Ren, J. T.; Yuan, G. G.; Weng, C. C.; Chen, L.; Yuan, Z. Y. Uniquely integrated Fe-doped Ni(OH) 2 nanosheets for highly efficient oxygen and hydrogen evolution reactions. Nanoscale 2018, 10, 10620-10628, DOI 10.1039/c8nr01655k.

(49) Ren, J. T.; Yuan, Z. Y. Hierarchical Nickel Sulfide Nanosheets Directly Grown on Ni Foam: A Stable and Efficient Electrocatalyst for Water Reduction and Oxidation in Alkaline Medium. ACS Sustainable Chem. Eng. 2017, 5, 7203-7210, DOI 10.1021/acssuschemeng.7b01419.

(50) Wang, C.; Jiang, J.; Ding, T.; Chen, G.; Xu, W.; Yang, Q. Monodisperse Ternary NiCoP Nanostructures as a Bifunctional Electrocatalyst for Both Hydrogen and Oxygen Evolution Reactions with Excellent Performance. Adv. Mater. Interfaces 2015, 3, 1500454, DOI 10.1002/admi.201500454. 
(51) Sivanantham, A.; Ganesan, P.; Shanmugam, S. Hierarchical $\mathrm{NiCo}_{2} \mathrm{~S}_{4}$ Nanowire Arrays Supported on Ni Foam: An Efficient and Durable Bifunctional Electrocatalyst for Oxygen and Hydrogen Evolution Reactions. Adv. Funct. Mater. 2016, 26, 4661-4672, DOI 10.1002/adfm.201600566. (52) Jiang, N.; You, B.; Sheng, M.; Sun, Y. Electrodeposited Cobalt-Phosphorous-Derived Films as Competent Bifunctional Catalysts for Overall Water Splitting. Angew. Chem. Int. Ed. 2015, 54, 6251-6254, DOI 10.1002/anie.201501616..

(53) Tang, C.; Cheng, N.; Pu, Z.; Xing, W.; Sun, X. NiSe Nanowire Film Supported on Nickel Foam: An Efficient and Stable 3D Bifunctional Electrode for Full Water Splitting. Angew. Chem. Int. Ed. 2015, 54, 9351-9355, DOI 10.1002/anie.201503407..

(54) Zhu, Y. P.; Liu, Y. P.; Ren, T. Z.; Yuan, Z. Y. Self - Supported Cobalt Phosphide Mesoporous Nanorod Arrays: A Flexible and Bifunctional Electrode for Highly Active Electrocatalytic Water Reduction and Oxidation. Adv. Funct. Mater. 2015, 25, 7337-7347, DOI 10.1002/adfm.201503666. (55) Tang, C.; Cheng, N.; Pu, Z.; Xing, W.; Sun, X. NiSe nanowire film supported on nickel foam: an efficient and stable 3D bifunctional electrode for full water splitting. Angew. Chem. Int. Ed. 2015, 127, 9483-9487, DOI 10.1002/anie.201503407.

(56) Li, M.; Zhu, Y.; Wang, H.; Wang, C.; Pinna, N.; Lu, X. Ni Strongly Coupled with $\mathrm{Mo}_{2} \mathrm{C}$ Encapsulated in Nitrogen-Doped Carbon Nanofibers as Robust Bifunctional Catalyst for Overall Water Splitting. Adv. Energy Mater. 2019, 9, 1803185, DOI 10.1002/aenm.201803185..

(57) Zhu, W.; Yue, X.; Zhang, W.; Yu, S.; Zhang, Y.; Wang, J.; Wang, J. Nickel sulfide microsphere film on Ni foam as an efficient bifunctional electrocatalyst for overall water splitting. Chem. Commun. 2016, 52, 1486-1489, DOI 10.1039/c5cc08064a..

(58) Tian, J.; Cheng, N.; Liu, Q.; Sun, X.; He, Y.; Asiri, A. M. Self-supported NiMo hollow nanorod array: an efficient 3D bifunctional catalytic electrode for overall water splitting. J. Mater. Chem. A 2015, 3, 20056-20059, DOI 10.1039/c5ta04723d..

(59) Huang, C.; Ouyang, T.; Zou, Y.; Li, N.; Liu, Z.-Q. Ultrathin NiCo2Px nanosheets strongly coupled with CNTs as efficient and robust electrocatalysts for overall water splitting. J. Mater. Chem. A 2018, 6, 7420-7427, DOI 10.1039/c7ta11364a..

(60) Li, X.; Wang, X.; Zhou, J.; Han, L.; Sun, C.; Wang, Q.; Su, Z. Ternary hybrids as efficient bifunctional electrocatalysts derived from bimetallic metal-organic-frameworks for overall water splitting. J. Mater. Chem. A 2018, 6, 5789-5796, DOI 10.1039/c7ta10558d.

(61) Jiang, H.; Gu, J.; Zheng, X.; Liu, M.; Qiu, X.; Wang, L.; Li, W.; Chen, Z.; Ji, X.; Li, J. Defect-rich and ultrathin N doped carbon nanosheets as advanced trifunctional metal-free electrocatalysts for the ORR, OER and HER. Energy Environ. Sci. 2019, 12, 322-333, DOI 10.1039/C8EE03276A.

(62) Zhang, C.; Zhang, G.; Li, H.; Chang, Y.; Chang, Z.; Liu, J.; Sun, X. Interfacial dehalogenation-enabled hollow N-doped carbon network as bifunctional catalysts for rechargeable Zn-air battery. Electrochim. Acta 2017, 247, 1044-1051, DOI 10.1016/j.electacta.2017.07.099.

(63) Wang, S.; Qin, J.; Meng, T.; Cao, M. Metal-organic framework-induced construction of actiniae-like carbon nanotube assembly as advanced multifunctional electrocatalysts for overall water splitting and Zn-air batteries. Nano Energy 2017, 39, 626-638 DOI 10.1016/j.nanoen.2017.07.043..

(64) Pei, Z. X.; Li, H. F.; Huang, Y.; Xue, Q.; Huang, Y.; Zhu, M. S.; Wang, Z. F.; Zhi, C. Y. Texturing in situ: N, S-enriched hierarchically porous carbon as a highly active reversible oxygen electrocatalyst. Energy Environ. Sci. 2017, 10, 742-749, DOI 10.1039/c6ee03265f.

(65) Shinde, S. S.; Lee, C. H.; Sami, A.; Kim, D. H.; Lee, S. U.; Lee, J. H. Scalable 3-D Carbon Nitride Sponge as an Efficient Metal-Free Bifunctional Oxygen Electrocatalyst for Rechargeable Zn-Air Batteries. ACS Nano 2017, 11, 347-357, DOI 10.1021/acsnano.6b05914.. 
(66) Zhang, X.; Liu, R.; Zang, Y.; Liu, G.; Wang, G.; Zhang, Y.; Zhang, H.; Zhao, H. Co/CoO nanoparticles immobilized on Co-N-doped carbon as trifunctional electrocatalysts for oxygen reduction, oxygen evolution and hydrogen evolution reactions. Chem. Commun. 2016, 52, 5946-5949, DOI $10.1039 / \mathrm{c} 6 \mathrm{cc} 02513 \mathrm{~g}$.

(67) Yin, J.; Li, Y.; Lv, F.; Fan, Q.; Zhao, Y. Q.; Zhang, Q.; Wang, W.; Cheng, F.; Xi, P.; Guo, S. NiO/CoN Porous Nanowires as Efficient Bifunctional Catalysts for Zn-Air Batteries. ACS Nano 2017, 11, 2275-2283, DOI 10.1021/acsnano.7b00417..

(68) Fu, G.; Cui, Z.; Chen, Y.; Li, Y.; Tang, Y.; Goodenough, J. B. Ni 3 Fe-N Doped Carbon Sheets as a Bifunctional Electrocatalyst for Air Cathodes. Adv. Energy Mater. 2016, 7, 1601172, DOI 10.1002/aenm.201601172.

(69) Wu, X.; Han, X.; Ma, X.; Zhang, W.; Deng, Y.; Zhong, C.; Hu, W. Morphology-Controllable Synthesis of Zn-Co-Mixed Sulfide Nanostructures on Carbon Fiber Paper Toward Efficient Rechargeable Zinc-Air Batteries and Water Electrolysis. ACS Appl. Mater. Interfaces 2017, 9 , 12574-12583, DOI 10.1021/acsami.6b16602.

(70) Chen, Y.; Guo, Y.; Cui, H.; Xie, Z.; Zhang, X.; Wei, J.; Zhou, Z. Bifunctional Electrocatalysts of MOF-Derived Co-N/C on Bamboo-Like MnO Nanowires for High-Performance Liquid and Solid-State Zn-Air Batteries. J. Mater. Chem. A 2018, 6, 9716-9722, DOI 10.1039/c8ta01859f.

(71) Li, Y.; Zhong, C.; Liu, J.; Zeng, X.; Qu, S.; Han, X.; Deng, Y.; Hu, W.; Lu, J. Atomically Thin Mesoporous $\mathrm{Co}_{3} \mathrm{O}_{4} \mathrm{Layers} \mathrm{Strongly} \mathrm{Coupled}$ with N - rGO Nanosheets as High - Performance Bifunctional Catalysts for 1D Knittable Zinc-Air Batteries. Adv. Mater. 2018, 30, 1703657, DOI 10.1002/adma.201703657.

(72) Wei, L.; Karahan, H. E.; Zhai, S.; Liu, H.; Chen, X.; Zhou, Z.; Lei, Y.; Liu, Z.; Chen, Y. Amorphous Bimetallic Oxide-Graphene Hybrids as Bifunctional Oxygen Electrocatalysts for Rechargeable Zn-Air Batteries. Adv. Mater. 2017, 29, 1701410, DOI 10.1002/adma.201701410.

(73) Wang, H. F.; Tang, C.; Wang, B.; Li, B. Q.; Zhang, Q. Bifunctional Transition Metal Hydroxysulfides: Room - Temperature Sulfurization and Their Applications in Zn-Air Batteries. Adv. Mater. 2017, 29, 1702327, DOI 10.1002/adma.201702327.

(74) Tian, W.; Li, H.; Qin, B.; Xu, Y.; Hao, Y.; Li, Y.; Zhang, G.; Liu, J.; Sun, X.; Duan, X. Tuning the wettability of carbon nanotube arrays for efficient bifunctional catalysts and Zn-air batteries. J. Mater. Chem. A 2017, 5, 7103-7110, DOI 10.1039/C6TA10505J.

(75) Tang, C.; Wang, B.; Wang, H. F.; Zhang, Q. Defect Engineering toward Atomic Co-Nx-C in Hierarchical Graphene for Rechargeable Flexible Solid Zn - Air Batteries. Adv. Mater. 2017, 29, 1703185, DOI 10.1002/adma.201703185.

(76) Niu, W.; Li, Z.; Marcus, K.; Zhou, L.; Li, Y.; Ye, R.; Liang, K.; Yang, Y. Surface - Modified Porous Carbon Nitride Composites as Highly Efficient Electrocatalyst for Zn - Air Batteries. Adv. Energy Mater. 2018, 8, 1701642, DOI 10.1002/aenm.201701642.

(77) Guo, Z.; Li, C.; Li, W.; Guo, H.; Su, X.; He, P.; Wang, Y.; Xia, Y. Ruthenium oxide coated ordered mesoporous carbon nanofiber arrays: a highly bifunctional oxygen electrocatalyst for rechargeable Zn-air batteries. J. Mater. Chem. A 2016, 4, 6282-6289, DOI 10.1039/c6ta02030e.

(78) Zhang, M.; Dai, Q.; Zheng, H.; Chen, M.; Dai, L. Novel MOF - Derived Co@ N - C Bifunctional Catalysts for Highly Efficient Zn-Air Batteries and Water Splitting. Adv. Mater. 2018, 30, 1705431, DOI 10.1002/adma.201705431. 